\title{
Calcium Channel Subunit $\alpha 2 \delta 4$ Is Regulated by Early Growth Response 1 and Facilitates Epileptogenesis
}

\author{
๑Daren M.J. van Loo, ${ }^{1}$ Christine K. Rummel, ${ }^{1}$ OJulika Pitsch, ${ }^{1}$ - Johannes Alexander Müller, ${ }^{1}$ Arthur F. Bikbaev, ${ }^{2}$

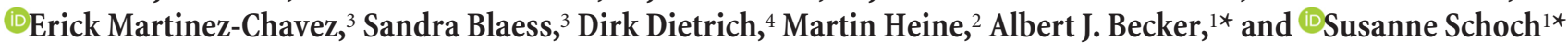 \\ ${ }^{1}$ Section for Translational Epilepsy Research, Department of Neuropathology, University of Bonn Medical Center, 53105 Bonn, Germany, ${ }^{2 R G}$ Molecular \\ Physiology, Leibniz Institute for Neurobiology, Center for Behavioral Brain Science, Otto-von-Guericke-University of Magdeburg, 39118 Magdeburg, \\ Germany, ${ }^{3}$ Institute of Reconstructive Neurobiology, University of Bonn Medical Center, 53105 Bonn, Germany, and ${ }^{4}$ Department of Neurosurgery, \\ University of Bonn Medical Center, 53105 Bonn, Germany
}

Transient brain insults, including status epilepticus (SE), can trigger a period of epileptogenesis during which functional and structural reorganization of neuronal networks occurs resulting in the onset of focal epileptic seizures. In recent years, mechanisms that regulate the dynamic transcription of individual genes during epileptogenesis and thereby contribute to the development of a hyperexcitable neuronal network have been elucidated. Our own results have shown early growth response 1 (Egr1) to transiently increase expression of the T-type voltage-dependent $\mathrm{Ca}^{2+}$ channel (VDCC) subunit $\mathrm{Ca}_{\mathrm{v}} 3.2$, a key proepileptogenic protein. However, epileptogenesis involves complex and dynamic transcriptomic alterations; and so far, our understanding of the transcriptional control mechanism of gene regulatory networks that act in the same processes is limited. Here, we have analyzed whether Egrl acts as a key transcriptional regulator for genes contributing to the development of hyperexcitability during epileptogenesis. We found Egr 1 to drive the expression of the VDCC subunit $\alpha 2 \delta 4$, which was augmented early and persistently after pilocarpine-induced SE. Furthermore, we show that increasing levels of $\alpha 2 \delta 4$ in the CA1 region of the hippocampus elevate seizure susceptibility of mice by slightly decreasing local network activity. Interestingly, we also detected increased expression levels of Egrl and $\alpha 2 \delta 4$ in human hippocampal biopsies obtained from epilepsy surgery. In conclusion, Egrl controls the abundance of the VDCC subunits $\mathrm{Ca}_{\mathrm{V}} 3.2$ and $\alpha 2 \delta 4$, which act synergistically in epileptogenesis, and thereby contributes to a seizure-induced "transcriptional $\mathrm{Ca}^{2+}$ channelopathy."

Key words: Cacna2d4; CaV3.2; early growth response 1; epileptogenesis; pilocarpine and kainic acid-induced status epilepticus; transcriptional $\mathrm{Ca}^{2+}$ channelopathy

Significance Statement

The onset of focal recurrent seizures often occurs after an epileptogenic process induced by transient insults to the brain. Recently, transcriptional control mechanisms for individual genes involved in converting neurons hyperexcitable have been identified, including early growth response 1 (Egr1), which activates transcription of the T-type $\mathrm{Ca}^{2+}$ channel subunit $\mathrm{Ca}_{\mathrm{v}} 3.2$. Here, we find Egr 1 to regulate also the expression of the voltage-dependent $\mathrm{Ca}^{2+}$ channel subunit $\alpha 2 \delta 4$, which was augmented after pilocarpineand kainic acid-induced status epilepticus. In addition, we observed that $\alpha 2 \delta 4$ affected spontaneous network activity and the susceptibility for seizure induction. Furthermore, we detected corresponding dynamics in human biopsies from epilepsy patients. In conclusion, Egrl orchestrates a seizure-induced "transcriptional $\mathrm{Ca}^{2+}$ channelopathy" consisting of $\mathrm{Ca}_{\mathrm{V}} 3.2$ and $\alpha 2 \delta 4$, which act synergistically in epileptogenesis.

\section{Introduction}

Transient brain insults, including status epilepticus (SE), can induce a process called epileptogenesis and render neuronal networks chronically hyperexcitable. Epileptogenesis refers to the

Received July 10, 2018; revised Dec. 3, 2018; accepted Jan. 8, 2019.

Author contributions: K.M.J.v.L., S.B., D.D., M.H., A.J.B., and S.S. designed research; K.M.J.v.L., C.K.R., J.P., J.A.M., A.F.B., and E.M.C. performed research; K.M.J.v.L., C.K.R., J.P., J.A.M., A.F.B., E.M.C., S.B., and D.D. analyzed data; K.M.J.v.L. wrote the first draft of the paper; D.D., M.H., A.J.B., and S.S. edited the paper. period during which the "central nervous tissue acquires the capability to generate spontaneous seizures" and relates to "the development of an epileptic condition” (Pitkänen and Engel, 2014). 
The transcriptome of human brain biopsies of pharmacoresistant focal epilepsy patients undergoing surgery for seizure control and of corresponding rodent models exhibits strong changes in the expression levels of a large number of genes compared with healthy hippocampus (Laurén et al., 2010; Okamoto et al., 2010; Hansen et al., 2014; Johnson et al., 2015). Many of these genes code for proteins with substantial impact on neuronal excitability, in particular distinct ion channels (Ellerkmann et al., 2003; Bernard et al., 2004; Royeck et al., 2015; van Loo et al., 2015; Gross et al., 2016).

Recently, we have observed an acquired channelopathy, in which the $\mathrm{Ca}_{\mathrm{v}} 3.2$-mRNA encoding the low voltage-dependent pore-forming $\mathrm{Ca}^{2+}$ channel subunit $\alpha 1 \mathrm{H}$ is transiently augmented during epileptogenesis after pilocarpine-induced SE (Su et al., 2002; Becker et al., 2008). This translates into increased $\mathrm{Ca}_{\mathrm{V}} 3.2$ protein levels and T-type $\mathrm{Ca}^{2+}$ currents, as well as a higher propensity of CA1 neurons for burst discharges (Sanabria et al., 2001). $\mathrm{Ca}_{\mathrm{v}}$ 3.2-deficient mice do not show these electrophysiological changes during epileptogenesis and experience dramatically fewer chronic recurrent seizures (Becker et al., 2008).

The theory of "master regulators" controlling the transcriptional dynamics of genes involved in epileptogenesis is attractive because this would mean that blocking these transcriptional regulators could be particularly powerful in exerting antiepileptogenic and disease-modifying effects. Numerous "master regulator candidates," comprising transcriptional activators and repressors, have been suggested (for review, see Becker, 2018). However, only few reports so far have demonstrated the regulation of more than one gene encoding a protein integrally involved in the processes underlying epileptogenesis by a single transcription factor (TF) (McClelland et al., 2014).

With respect to potential control mechanisms, we have observed substantial promoter activation of $\mathrm{Ca}_{\mathrm{V}} 3.2$ by the immediate early TF Egr1 (van Loo et al., 2012). Here, we addressed the question whether Egr1 is a hub gene in an epileptogenic gene regulatory network that controls the seizure-induced expression of not only $\mathrm{Ca}_{\mathrm{v}} 3.2$, but also of additional potentially diseaserelevant voltage-dependent calcium channels (VDCCs). $\mathrm{Ca}^{2+}$ channels consist of a complex of pore forming $\alpha 1$ and auxiliary $\alpha 2 \delta, \beta$, and $\gamma$ subunits (Catterall, 2000). In particular, members of the CACNA2D family have been linked to various forms of epilepsy, including CACNA2D1 to West syndrome (Hino-Fukuyo et al., 2015) and symptomatic generalized epilepsy (Vergult et al., 2015), and CACNA2D2 to infantile epileptic encephalopathy (Edvardson et al., 2013; Pippucci et al., 2013). Genetic mutations or rearrangements of the mouse Cacna2 $d 2$ gene can result in an epileptic phenotype, as seen in the $d u c k y, d u c k y^{2 j}$, and entla mice (Barclay et al., 2001; Brill et al., 2004). Moreover, Gabapentin, an adjunct drug to control seizures, was found to bind both the $\alpha 2 \delta 1$ and $\alpha 2 \delta 2$ subunits. These findings support the idea that other high voltageactivated calcium channels may play a role in the pathogenesis of epilepsy.

Here, we observed a strong positive regulation of Cacna $2 d 4$ by Egr1, which encodes the auxiliary $\alpha 2 \delta 4(\alpha 2 \delta 4)$ VDCC subunit. $\alpha 2 \delta 4$, so far known to be expressed at higher levels only in the

\footnotetext{
program of the University of Bonn Medical Center. We acknowledge the assistance of the Viral Core Facility of the University of Bonn, supported in part by SFB1089. We thank Lioba Dammer, Anna Dorißen, and Sabine Opitz for excellent technical assistance; and Rebecca Kulbida for providing materials for this study.

The authors declare no competing financial interests.

*A.J.B. and S.S. contributed equally to this work.

Correspondence should be addressed to Karen M.J.van Loo at Karen.van_loo@ukb.uni-bonn.de.

https://doi.org/10.1523/JNEUROSCI.1731-18.2019

Copyright $\odot 2019$ the authors
}

retina (Wycisk et al., 2006a), was found to act proepileptogenic. Together, our data provide the first evidence for a synergistic transcriptional $\mathrm{Ca}^{2+}$ channelopathy, based on an Egrl-mediated dynamic augmentation of the $\mathrm{Ca}_{\mathrm{v}} 3.2$ and $\alpha 2 \delta 4$ calcium channel subunits.

\section{Materials and Methods}

Bioinformatic analysis. Enriched, overrepresented binding sites for Egr1 were identified using the Genomatix RegionMiner software tool (RRID: SCR_008036) and ranked based on their overrepresentation value calculated against (1) the whole genome ( $Z$ score-genome) and against (2) all annotated promoter regions of the genome ( $Z$ score-promoter). A $Z$ score $>2$ corresponds to a $p$ value of 0.05 and can be considered statistically significant (Ho Sui et al., 2005).

As calcium channel genes, we selected Cacnala, Cacnalb, Cacnalc, Cacnald, Cacnale, Cacnalf, Cacnalg, Cacnalh, Cacnali, Cacnals, Cacna2d1, Cacna2d2, Cacna2d3, Cacna2d4, Cacnb1, Cacnb2, Cacnb3, Cacnb4, and Cacng1. In contrast to the Cacnag1 gene, which was found to be a calcium channel subunit (Takahashi et al., 1987), the Cacng2-8 genes were not included in our analysis because no biochemical or functional evidence supports a role for these proteins as calcium channel subunits (Witcher et al., 1993; Müller et al., 2010; Catterall, 2011). Rather, Cacng2-8 genes belong to the group of transmembrane AMPA receptor regulatory proteins (Tomita et al., 2003).

The genomic sequence of the mouse Cacna2d4 gene was obtained from the UCSC genome browser (December 2011; GRCm38/mm10; RRID:SCR_005780). Potential transcriptional start sites (TSSs) and TATA box motifs were identified using GPMiner (Lee et al., 2012), and Egrl binding sites within the Cacna2d4 promoter region were identified using the Genomatix MathInspector software tool.

Plasmids. The pAAV-hSyn-tdTomato and pAAV-hSyn-GFP plasmids were made by cloning the tdTomato and GFP sequences into the BamHI/ BglII-digested pAAV-hSyn-Venus vector (van Loo et al., 2015). The pAAV-hSyn-Egr1-IRES-Venus construct was made by introducing the mouse Egrl gene (van Loo et al., 2012) into pAAV-hSyn-IRES-Venus (van Loo et al., 2015) using the NheI and BamHI restriction sites. pAAVhSyn-Egr1dN-2A-mCherry was made by first introducing the Egr1 gene into pKan-CMV-2A-mCherry (kind gift from D. Wachten, Bonn University) using EcoRI/HindIII. Next, the zinc-binding domain of Egr 1 was deleted by digestion and subsequent ligation of the pKan-CMV-Egr1$2 \mathrm{~A}-\mathrm{mCherry}$ construct with XmnI. Using this strategy, a $282 \mathrm{bp}$ fragment is removed, resulting in a dominant-negative version of the Egrl gene (EgrldN; (Cao et al., 1990). As a next step, the EgrldN-2A-mCherry fragment was inserted into pAAV-hSyn-MCS using EcoRI/BamHI. The pAAV-hSyn-Cacna2d4-2A-mCherry plasmid was produced by first introducing the human Cacna2d4 gene (kind gift from Dr. F. Haeseleer, University of Washington) (Lee et al., 2015) into pAAV-hSyn-MCS using AsiSI/ClaI. Then, the 2A-mCherry sequence (see above) was introduced into BshVI/SalI-digested pAAV-hSyn-Cacna2d4 using the In-Fusion HD Cloning kit (Takara Bio) with forward $5^{\prime}$-aactcctgcggatcggagtgaa acagactttgaattttgaccttct- $3^{\prime}$ and reverse $5^{\prime}$-gcttctgcaggtcgatcacttgtacag ctcg- $3^{\prime}$ primers. pLenti-hSyn-Cacna2d1-HA was made using a pLentivector of the second generation (pLenti-synapsin-ChR2; provided by Thomas Oertner and Tobias Rose; FMI Basel). The ChR2 insert was removed by digestion with AgeI and BsrGI, and sticky ends were afterward filled up using Klenow Fragment (Thermo Fisher Scientific). The Cacna2d1-2HA insert (NM_001082276.1) was cut from a pCBA- $\alpha 2 \delta 1$ 2HA plasmid (provided by Gerald Obermaier) using NotI and SalI, filled up to blunt ends, and ligated into the lentiviral transfer vector. All cloning procedures were performed in Stbl2 bacteria (Invitrogen). Plasmid sequences were verified by sequencing analysis.

Cell culture and virus production. NG108-15 cells (ATCC HB12317TM, RRID:CVCL_0464) were maintained at $37^{\circ} \mathrm{C}$ and $5 \% \mathrm{CO}_{2}$ in DMEM supplemented with $10 \%(\mathrm{v} / \mathrm{v})$ heat-inactivated FCS (Invitrogen), $100 \mathrm{units} / \mathrm{ml}$ penicillin/streptomycin, $2 \mathrm{~mm}$ glutamine, and $1 \times$ HAT (sodium hypoxanthine, aminopterin, and thymidine; Invitrogen). HEK293-AAV cells (\#240073, RRID:CVCL_6871, Stratagene) were kept in high glucose DMEM supplemented with 10\% FCS (Invitrogen), 100 
units $/ \mathrm{ml}$ penicillin/streptomycin, and $2 \mathrm{~mm}$ glutamine, and incubated at $37^{\circ} \mathrm{C}$ and $5 \% \mathrm{CO}_{2}$. Recombinant AAV1/2 genomes were generated by large-scale triple $\mathrm{CaPO}_{4}$ transfection of HEK293-AAV cells as described previously (van Loo et al., 2012).

To produce lentiviruses, $3 \times 10^{6}$ HEK293T cells were seeded on a 10 $\mathrm{cm}$ cell culture dish and transfected after $24 \mathrm{~h}$ with a second-generation lentiviral packaging system $(7.5 \mu \mathrm{g}$ psPax2, Addgene \#12260; $5 \mu \mathrm{g}$ pMD2.G, Addgene \#12259; and $4 \mu \mathrm{g}$ pLenti-hSyn-Cacna2d1-HA) using GenJet transfection reagent (Signagen). Cells were incubated for $12 \mathrm{~h}$ at $37^{\circ} \mathrm{C}$ and $5 \% \mathrm{CO}_{2}$, and medium was replaced to fresh DMEM containing Glutamax (Invitrogen) supplemented with 10\% FBS. After $72 \mathrm{~h}$ of incubation, supernatant was filtered through $0.45 \mu \mathrm{m}$ PVDF membrane filters (GE Healthcare) and collected in conical ultracentrifugation tubes (Beckman Coulter). The filtered supernatant was under layered by OptiPrep solution (Sigma-Aldrich) and centrifuged at $24,000 \mathrm{rpm}$ for $2 \mathrm{~h}$ at $4^{\circ} \mathrm{C}$ in a SW-Ti32 swinging bucket (Beckman Coulter). The upper layer was discarded, and the OptiPrep-Layer with viral particles at its top was gently mixed with TBS-5 buffer (containing the following: $50 \mathrm{~mm}$ Tris$\mathrm{HCl}, 130 \mathrm{~mm} \mathrm{NaCl}, 10 \mathrm{~mm} \mathrm{KCl}, 5 \mathrm{~mm} \mathrm{MgCl}_{2}$ ). Suspension was centrifuged as before to pellet the viral particles. Supernatant was discarded, and the pellet was resuspended in TBS- 5 buffer. Lentiviral particles were stored at $-80^{\circ} \mathrm{C}$ until use.

$m R N A$ isolation and real-time RT-PCR quantification. mRNA and cDNA from NG108-15 cell preparations and hippocampi were isolated using the Dynabeads mRNA Direct Micro Kit (Invitrogen) and the RevertAid Premium First strand cDNA Synthesis Kit (Fermentas), respectively. mRNA quantification was performed by real-time RT-PCR using the $\Delta \Delta \mathrm{C}_{\mathrm{t}}$-method. Quantitative PCR was performed in an ABI Prism 7900HT apparatus (PE Applied Biosystems) containing $1 \times$ Maxima SYBR Green/ROX qPCR Master Mix (Fermentas), 5 pM each oligonucleotide primer (Synaptophysin: 5'-TTCAGGACTCAACACCTCGGT-3 and 5'-CACGAACCATAGGTTGCCAAC-3'; Cacna2d4: 5' -CTGCCAG AAGACATTCGTGA- $3^{\prime}$ and $5^{\prime}$-TTTGACTTCTGTGGCCTCCT- ${ }^{\prime}$; Cacng5: 5'-CGAGATGCTCAACAGAACCA-3' and 5'-AGACATCA CCCCAGCACTCT-3'; Cacna1s: 5' -CCCCGTGCCAGGTAACA-3' and 5'-GAGCCTCCTGGATCAGCAT-3'; Cacnal h: 5'-TCATCTTCGGCA TCGTTGG-3' and 5'-CGCAAGAAGGTCAGGTTGTTG-3'; Egr1: 5' GGAGCCGAGCGAACAACCCT- $3^{\prime}$ and $5^{\prime}$-TCCAGGGAGAAGCGGC CAGT- $3^{\prime}$ ) and $1 / 10$ synthesized cDNA (total volume of $6.25 \mu \mathrm{l}$ ), by incubating $2 \mathrm{~min}$ at $50^{\circ} \mathrm{C}, 10 \mathrm{~min}$ at $95^{\circ} \mathrm{C}, 40$ cycles of $15 \mathrm{~s}$ at $95^{\circ} \mathrm{C}$ and 1 $\min$ at $59^{\circ} \mathrm{C}$. Quantification was based on synaptophysin (Chen et al., 2001).

$I S H$. Mice were deeply anesthetized with $16 \mathrm{mg} / \mathrm{kg}$ xylazine (Rompun; Bayer) and $100 \mathrm{mg} / \mathrm{kg}$ ketamine, i.p. (Ketavet; Pfizer) and were transcardially perfused with $4 \%$ PFA. Brains were removed and postfixed in $4 \%$ PFA overnight at $4^{\circ} \mathrm{C}$. Brains were then rinsed in PBS and cryoprotected in ascending sucrose series (10\%,20\%, and $30 \%$ in PBS), and $20-\mu \mathrm{m}-$ thick sections were cut on a cryostat. ISH on frozen sections was performed using RNAscope Fluorescent Multiplex Detection Reagents (323110, ACDBio) according to the manufacturer's instructions for fixed frozen tissue (User Manual: 323100-USM). Probes (Mm-Egr1-C3: 423371-C3 and Mm-Cacna2d4-C2:487531-C2) were designed by ACDBio. Sections were counterstained with Hoechst (Sigma-Aldrich), then rinsed twice in TBS-T (5 min) and twice in TBS. Sections were mounted with Aqua-PolyMount (18606, Polysciences) and imaged on an Axio Observer inverted fluorescence microscope (Carl Zeiss) using $40 \times$ or $63 \times$ objectives (EC Plan-Neofluar, Carl Zeiss) and structured illumination (ApoTome, Carl Zeiss). Images taken with the $63 \times$ objective are maximum intensity projections of $Z$ stacks. AxioVision MosaiX software was used to stitch images.

Transfection and Luciferase assay. NG108-15 cells were transfected using Lipofectamine 2000 (Invitrogen) in 48-well plates. Per well, $0.05 \mu \mathrm{g}$ of pAAV-Ca 3 3.2FL-Luciferase (Kulbida et al., 2015), $0.0125 \mu \mathrm{g}$ of $R e-$ nilla control vector (pRL-TK; Promega), together with the amount of Egr1/EgrldN plasmids as indicated, were mixed with $0.5 \mu$ lipofectamine and $25 \mu \mathrm{l}$ OPTI-MEM (Invitrogen) and added to the wells after 20 min incubation. Cells were grown in Opti-MEM (Invitrogen) for $16 \mathrm{~h}$. Then, the serum-free medium was replaced by normal NG108-15 medium (see above); and $36 \mathrm{~h}$ after transfection, a luciferase assay was performed using the Dual Luciferase Reporter Assay System (Promega), as described previously (van Loo et al., 2015).

Chromatin immunoprecipitation (ChIP) assays. ChIPs on NG108-15 cells and total hippocampi were performed as described previously (van Loo et al., 2015) using the SimpleChIP Plus Enzymatic chromatin IP kit (Cell Signaling Technology; \#9005) with $5 \mu \mathrm{g}$ anti-Egr 1 (SC-110, RRID: AB_2097174, Santa Cruz Biotechnology). The recovered DNA and the corresponding Input-DNA samples were analyzed by PCR with primers spanning the putative Egr1-binding sites in the Cacna2d4 promoter region (see Fig. 3A; ChIP1: 5' -ACCTTGGAGCAGGTCGAAAC-3' and 5' TGGAAACCTAGGACCCTACCC-3'; ChIP2: 5' -GATGTGCACCTCCA AGGCA-3' and 5' -TGGTGTGGTTCACGTTTCCA-3' ${ }^{\prime}$; ChIP3/4: 5' -CA GAGCCTAGCCCACAAAG-3' and $5^{\prime}$-TGCCCTTCTGCTCCAAAGA G-3'; ChIP5: 5'-AGAGGAGAGGCCAGTGGATT-3' and 5'-AGCCCC TGCTGGGAGATAA-3'; ChIP6: 5'-TGGCAGCAAGTTATCTCCCA G-3' and 5'-CCACAGGATGATTGGCGTCT-3'). PCRs included $1 \mu \mathrm{l}$ input/immunoprecipitated DNA, 10 pmol of each primer, and $1 \times$ EconoTaq Plus Green Master Mix (Lucigen) in a $25 \mu \mathrm{l}$ reaction. Reactions were amplified at $94^{\circ} \mathrm{C}$ for $30 \mathrm{~s}, 58^{\circ} \mathrm{C}$ for $30 \mathrm{~s}$, and $72^{\circ} \mathrm{C}$ for $45 \mathrm{~s}$ for 35 cycles and analyzed on a $2 \%$ agarose gel.

Stereotactic viral vector injection. Mice were housed under a $12 \mathrm{~h}$ light/ dark cycle with food and water ad libitum. Adult male mice ( $\sim 56 \mathrm{~d},>20 \mathrm{~g})$ were obtained from Charles River (C57BL/6-N; MGI catalog \#5651595, RRID:MGI:5651595). Adeno-associated virus (AAV) and lentiviral injections ( $1 \mu \mathrm{l}$ of viral suspension) into the CA1 hippocampal region were performed as described previously (van Loo et al., 2015), at the coordinates (in $\mathrm{mm}$ ) -2 posterior, $-1.5 / 1.5$ lateral, and 1.5 ventral relative to bregma. All experiments were performed in accordance with the guidelines of the European Union and the University of Bonn Medical Center Animal Care Committee.

Pilocarpine- and kainic acid (KA)-induced SE. To induce SE by systemic injection of pilocarpine, adult male C57BL/6-N mice were first injected with $1 \mathrm{mg} / \mathrm{kg}$ (s.c.) scopolamine methyl nitrate (Sigma-Aldrich). Twenty minutes later, animals were injected with $335 \mathrm{mg} / \mathrm{kg}$ (s.c.) pilocarpine hydrochloride (Sigma-Aldrich). Forty minutes after SE onset, the mice were injected once with $4 \mathrm{mg} / \mathrm{kg}$ (s.c.) diazepam (Ratiopharm). Control mice were given scopolamine methyl nitrate and diazepam, but $0.9 \% \mathrm{NaCl}$ instead of pilocarpine.

For induction of SE by KA, 60-d-old male C57BL/6-N mice were anesthetized with $6 \mathrm{mg} / \mathrm{kg}$ xylazine (Rompun; Bayer) and 90-120 mg/kg ketamine, i.p. (Ketavet; Pfizer) and received analgesic treatment (5 $\mathrm{mg} / \mathrm{kg}$ ketoprofen, s.c.; Gabrilen); $70 \mathrm{nl} \mathrm{KA} \mathrm{(20} \mathrm{mM} \mathrm{solution)} \mathrm{was} \mathrm{in-}$ jected unilaterally in the cortex above the left hippocampal region (at the coordinates $-2 \mathrm{~mm}$ posterior, $-1.5 \mathrm{~mm}$ lateral, and $1.2 \mathrm{~mm}$ ventral relative to bregma) at a rate of $35 \mathrm{nl} / \mathrm{min}$ using a microprocessorcontrolled mini-pump (World Precision Instruments). After injection, the needle was left in place for $\sim 5 \mathrm{~min}$ before withdrawal. Then, the incision was closed and animals were visually observed to check for the occurrence of behavioral motor seizures. Sham-control animals were treated identically but received $0.9 \% \mathrm{NaCl}$ instead of KA.

Pentylenetetrazol (PTZ) model. Seizures were induced by repetitive intraperitoneal injections of PTZ every $10 \mathrm{~min}$. Each injection consisted of $10 \mathrm{mg} / \mathrm{kg}$ PTZ (Sigma-Aldrich) and was given until a seizure occurred. The total dose of PTZ per animal did not exceed $100 \mathrm{mg} / \mathrm{kg}$ (10 injections).

Human temporal lobe epilepsy (TLE) patients and mRNA expression analyses. For the human gene expression analysis, human hippocampal biopsy from patients with hippocampal sclerosis (HS; $n=79$ ) and patients with lesion-associated (low-grade neoplasms or dysplasia; $n=35$ ) chronic TLE from the surgery program of the Department of Neurosurgery (Bonn, Germany) were analyzed as described previously (van Loo et al., 2015). All procedures were conducted in accordance with the Declaration of Helsinki and approved by the Ethics Committee of the University of Bonn Medical Center. Informed written consent was obtained from all patients.

Recording and analysis of the network activity in hippocampal cultures. Dissociated hippocampal cultures were prepared from newborn C57BL/6 mouse (postnatal day 0). Suspension of dissociated hippocam- 
pal cells ( 1 million cells/ml) obtained after dissociation with trypsin was plated on poly-D-lysine-coated 60-electrode microelectrode arrays (MEAs) with interelectrode distance $200 \mu \mathrm{m}$ (MultiChannel Systems). After plating, all cultures were incubated in serum-free Neurobasal medium at $37^{\circ} \mathrm{C}$ in humidified atmosphere $\left(95 \%\right.$ air and $\left.5 \% \mathrm{CO}_{2}\right)$, with culture medium being partially replaced on a weekly basis. The neuronal network activity was sampled at $10 \mathrm{kHz}$ using MEA1060INV-BC system (MultiChannel Systems) at $37^{\circ} \mathrm{C}$ in an atmosphere with $95 \%$ air and $5 \%$ $\mathrm{CO}_{2}$. The detection of spikes and bursts as well as network burst analysis were performed as described previously (Bikbaev et al., 2015). Briefly, the analysis was performed on 10-min-long intervals for each culture at each time point using Spike2 software (Cambridge Electronic Design). The threshold-based ( \pm 7 SDs of spike-free noise) detection of spikes in highpass $(300 \mathrm{~Hz})$ filtered records was followed by identification of bursts ( $\geq 5$ spikes with interspike interval $\leq 100 \mathrm{~ms}$ ). The mean firing and bursting rates were calculated separately for each active electrode in each individual culture.

Modeling the time course of Egr1 and Cacna2d4 mRNA. We used numerical evaluations of the below set of differential equations to fit the temporal evolution of Cacna2d 4 mRNA by adjusting the rate constants for the decay of the only assumed intermediate Egr 1 protein and the rise and decay of Cacna2d4 mRNA. All levels were treated as relative levels to control/before SE and therefore assumed to be 1 before injection of pilocarpine (initial condition). The time course of Egrl mRNA levels was used as input to the model, and solving the differential equations with this input resulted in a predicted time course of Cacna2d4 mRNA. The difference between this predicted time course and the measured relative levels of Cacna2d 4 mRNA was minimized during the iterative fitting process by adjusting the 3 rate constants mentioned above (below $k_{2}, k_{3}$, $\mathrm{k}_{4}$ ). Egr $1 \mathrm{mRNA}$ levels were approximated by a linear interpolation of 0 and $2 \mathrm{~h}$ and a biexponential decay thereafter $(1+45.1 \times \exp (-(t-$ $2) / 1.76)+15.4 \times \exp (-(t-2) / 19.3$, red continuous line, [egr1] $(t))$. We solved the following two differential equations:

$$
\begin{gathered}
\frac{\partial[\text { Egr } 1 \text { prot }]}{\partial t}=k_{1}([\text { Egr } 1](t)-1)-k_{2}([\text { Egr } 1 \text { prot }]-1) \\
\frac{\partial[\text { Cacna } 2 d 4]}{\partial t}=k_{3}([\text { Egr } 1 \text { prot }]-1)-k_{4}([\text { Cacna } 2 d 4]-1)
\end{gathered}
$$

with

$1 / k_{1}=6 \mathrm{hrs}, 1 / k_{2}=\tau_{\text {off_Egrlprot }}, 1 / k_{3}=\tau_{\text {on_Cacna2d } 4}, 1 / k_{4}$

$$
=\tau_{\text {off_Cacna2d4. }} .
$$

The calculations were performed using the built-in fitting and numerical integration functions of Igor Pro 7 (Wavemetrics).

Experimental design and statistical analysis. All experiments were conducted in a blinded and randomized manner. Statistical analyses were performed using Prism 6.05 software (GraphPad, RRID: SCR_002798). Unless otherwise mentioned, Student's $t$ tests and repeated-measures ANOVA followed by Tukey's multiplecomparisons tests were used to calculate the statistical significance. Sample size $(n)$ per experiment was calculated using power analysis, with parameters set within the accuracy of the respective experiment. All results are given as mean \pm SEM.

\section{Results}

\section{Binding sites for Egr1 are strongly overrepresented in the regulatory regions of genes coding for VDCCs and their subunits}

Recently, we reported that the TF Egr 1 can regulate transcription of the Cacnal $h$ gene encoding the T-type calcium channel $\mathrm{Ca}_{\mathrm{V}} 3.2$ (van Loo et al., 2012). As the Egr TF family consists of four genes, we hypothesized that it may play a broader role in the transcriptional regulation of VDCCs. To probe this hypothesis, we first checked whether promoters of VDCCs and their subunits contain consensus binding sites for the Egr TF family. Interestingly,
Table 1. Overrepresentation of TF families in VDCCs and their subunits

\begin{tabular}{lllll}
\hline $\begin{array}{l}\text { TF } \\
\text { families }\end{array}$ & $\begin{array}{l}\text { Overrepresentation } \\
\text { (promoters) }\end{array}$ & $\begin{array}{l}\text { Zscore } \\
\text { (promoters) }\end{array}$ & $\begin{array}{l}\text { Overrepresentation } \\
\text { (genome) }\end{array}$ & $\begin{array}{l}\text { Zscore } \\
\text { (genome) }\end{array}$ \\
\hline V\$EGRF & 2.28 & 23.53 & 4.17 & 43.17 \\
V\$ZF02 & 2.13 & 20.19 & 3.75 & 37.07 \\
V\$KLFS & 1.76 & 18.19 & 2.52 & 30.38 \\
V\$ZTRE & 2.15 & 17.73 & 3.53 & 30.35 \\
V\$ZF07 & 2.54 & 16.64 & 3.75 & 24.47 \\
\hline
\end{tabular}

Table 2. Overrepresentation of Egr-family members in VDCCs and their subunits

\begin{tabular}{lllll}
\hline TF matrices & $\begin{array}{l}\text { Overrepresentation } \\
\text { (promoters) }\end{array}$ & $\begin{array}{l}\text { Zscore } \\
\text { (promoters) }\end{array}$ & $\begin{array}{l}\text { Overrepresentation } \\
\text { (genome) }\end{array}$ & $\begin{array}{l}\text { Zscore } \\
\text { (genome) }\end{array}$ \\
\hline V\$EGR1.04 & 2.73 & 17.67 & 5.67 & 33.15 \\
V\$EGR1.02 & 2.87 & 12.68 & 15.46 & 42.24 \\
V\$EGR1.03 & 2.28 & 12.49 & 4.68 & 25.10 \\
V\$EGR1.01 & 2.39 & 9.65 & 6.78 & 23.89 \\
V\$EGR2.02 & 2.14 & 7.39 & 2.86 & 10.46 \\
V\$EGR3.01 & 1.61 & 3.06 & 3.98 & 9.64 \\
V\$EGR2.01 & 1.05 & 0.29 & 1.45 & 2.89 \\
\hline
\end{tabular}

bioinformatic analysis using the Genomatix gene regulation tool revealed that consensus binding sites for the Egr-family are indeed highly overrepresented in the promoter regions of all VDCCs and their subunits (Table 1): more binding sites for Egrfamily members are present in these promoter regions, compared with either the total genome (4.2-fold overrepresentation; $Z$ score of 43.17) or other promoter regions (2.3-fold overrepresentation; $Z$ score of 23.53; for information on $Z$ score, see Materials and Methods). Further analysis of these consensus binding sites revealed that most of the Egr-family binding sites were consensus sequences specific for Egr1 (Table 2).

Next, we analyzed specifically all distinct promoter regions of genes coding for VDCCs and their subunits for Egr1 binding sites. For 13 of 19 VDCC promoter regions, a significant overrepresentation for Egr1 was observed, with the strongest overrepresentation for the Cacnal $h$ promoter region (228-fold overrepresentation; $Z$ score genome: 70.64; $Z$ score-promoters: 22.89). No Egr1 binding site was found for Cacnali, Cacnb2, and Cacnb4 (Table 3).

\section{Pilocarpine-induced SE augments transcription of four VDCC subunits}

Previously, we have shown that $3 \mathrm{~d}$ after pilocarpine-induced SE expression of $\mathrm{Ca}_{\mathrm{V}} 3.2$ (Cacna1h) was increased in the hippocampal CA1 area due to Egr1-dependent promoter activation (Becker et al., 2008; van Loo et al., 2012). We therefore examined whether the mRNAs of those VDCC subunits showing a strong overrepresentation of Egr1 binding sites in their promoter regions (Table 3) are also augmented after pilocarpine-induced SE. For this, we analyzed RNA-seq data from hippocampal CA1 $3 \mathrm{~d}$ after pilocarpine-induced SE. From the 13 VDCC-family members displaying overrepresented Egr1 binding sites, the mRNA levels of Cacna1s (13.7-fold) and Cacna2d4 (13.9-fold) were increased (Table 4). Subsequent quantitative RT-PCR confirmed significantly increased Cacna2d4 mRNA levels (13.4-fold; $p=0.0018$; Fig. 1A). The mRNA expression level of Cacna1s in the hippocampal CA1 area was found to be too low for reliable assessment by quantitative PCR $\left(\mathrm{C}_{\mathrm{t}}\right.$ values $\left.>33\right)$. In summary, these results indicate that, in addition to Cacnalh, also Cacna2d4 contains binding sites for Egr 1 and shows increased expression levels after pilocarpine-induced SE. 
Table 3. Overrepresentation of Egr1 binding sites in distinct VDCCs and their subunits

\begin{tabular}{llcccc}
\hline Gene & TF families & $\begin{array}{l}\text { Overrepresentation } \\
\text { (promoters) }\end{array}$ & $\begin{array}{l}\text { Zscore } \\
\text { (promoters) }\end{array}$ & $\begin{array}{l}\text { Overrepresentation } \\
\text { (genome) }\end{array}$ & $\begin{array}{c}\text { Zscore } \\
\text { (genome) }\end{array}$ \\
\hline CACNA1A & V\$EGR1.02 & 10.45 & 8.23 & 92.65 & 26.96 \\
CACNA1B & V\$EGR1.02 & 9.58 & 6.75 & 84.99 & 22.36 \\
CACNA1C & V\$EGR1.02 & 5.6 & 3.82 & 49.61 & 13.86 \\
CACNA1D & V\$EGR1.02 & 5.37 & 4.15 & 47.65 & 15.15 \\
CACNA1E & V\$EGR1.04 & 6.06 & 5.38 & 34.34 & 15.06 \\
CACNA1F & V\$EGR1.04 & 1.25 & -0.34 & 7.09 & 0.96 \\
CACNA1G & V\$EGR1.02 & 9.27 & 7.64 & 82.2 & 25.36 \\
CACNA1H & V\$EGR1.02 & 25.79 & 22.89 & 228.73 & 70.64 \\
CACNA1I & NoEGR1 binding site present in promoter region & & \\
CACNA1S & V\$EGR1.02 & 5.45 & 3.23 & 48.37 & 11.88 \\
CACNA2D1 & V\$EGR1.04 & 8.58 & 7.73 & 48.66 & 20.5 \\
CACNA2D2 & V\$EGR1.02 & 10.52 & 9.7 & 93.26 & 31.7 \\
CACNA2D3 & V\$EGR1.04 & 13.76 & 11.39 & 78.01 & 28.93 \\
CACNA2D4 & V\$EGR1.01 & 2.52 & 0.79 & 12.7 & 3.38 \\
CACNB1 & V\$EGR1.04 & 9.96 & 7.48 & 56.46 & 19.55 \\
CACNB2 & NoEGR1 binding site present in promoter region & & \\
CACNB3 & V\$EGR1.04 & 5.19 & 3.11 & 29.42 & 9.12 \\
CACNB4 & NoEGR1 binding site present in promoter region & & \\
CACNG1 & V\$EGR1.01 & 1.48 & -0.21 & 7.48 & 1 \\
\hline
\end{tabular}

Table 4. Fold change increase of mRNA expression levels of all VDCC family members in hippocampal CA1 $3 \mathrm{~d}$ after pilocarpine-induced SE

\begin{tabular}{lc}
\hline Gene & Fold change \\
\hline CACNA1A & 1.07532 \\
CACNA1B & -1.28107 \\
CACNA1C & -1.12952 \\
CACNA1D & 1.02173 \\
CACNA1E & -1.05455 \\
CACNA1F & 1.11745 \\
CACNA1G & 1.04704 \\
CACNA1H & 1.31722 \\
CACNA11 & -1.48171 \\
CACNA1S & 13.7301 \\
CACNA2D1 & -1.23762 \\
CACNA2D2 & -1.00901 \\
CACNA2D3 & -1.39173 \\
CACNA2D4 & 13.9104 \\
CACNB1 & -1.23753 \\
CACNB2 & -1.25199 \\
CACNB3 & -1.4152 \\
CACNB4 & -1.39401 \\
CACNG1 & not expressed \\
\hline
\end{tabular}

Suppression of Egr1 prevents pilocarpine-induced mRNA augmentation of $\boldsymbol{C a}_{V} 3.2$ and Cacna2d 4

To assess whether the pilocarpine-induced augmentation of the VDCCs Cacna1h and Cacna2d4 is indeed caused by Egr 1 activation, we decided to interfere with Egr1 expression levels in the pilocarpine SE-model using a dominant-negative variant of Egr 1 (Egr $1 \mathrm{dN}$ ). Egr $1 \mathrm{dN}$ contains the DNA-binding domain but lacks the activating domain (see Materials and Methods). Upon overexpression, it blocks the access of the endogenous Egr1 to its binding site and thereby acts as a repressor of Egr1-mediated transcription. Using a Luciferase reporter assay in a neural cell line (NG108-15 cells), we verified the effectiveness of Egr1dN by showing that it dose-dependently suppressed Egr1-induced activation of the Cacnalh promoter (Fig. 1B). This construct was used further to generate AAVs containing EgrldN (rAAV-hSynEgrdN-2A-mCherry) and a control virus (rAAV-hSyn-tdTomato), either of which was injected into the hippocampal CA1 region of adult mice $(55 \mathrm{~d})$. Two weeks later, when stable expression levels of the viral transgene were achieved, mice underwent pilocarpine-SE or sham treatment. We killed mice $3 \mathrm{~d}$ after this treatment and micro-dissected the hippocampal CA1 regions. Treatment with Egr1dN (rAAV-hSyn-EgrdN-2A-mCherry) completely suppressed the pilocarpine-SE-induced increase in expression of Cacnalh as revealed by quantitative RT-PCR analysis $(p=0.0012$; Fig. $1 C)$. In addition, interfering with Egr 1 by viral overexpression of Egr1dN also significantly reduced the augmentation of Cacna2d4 mRNA levels ( $p=0.012$; Fig. $1 D)$. These results demonstrate that the pilocarpine SE-induced transcriptional increase of at least two VDCC family members, Cacna1h and Cacna2d4, critically depends on Egr1 signaling in vivo and that viral transduction with rAAV-hSyn-EgrdN-2AmCherry is an effective tool to interfere with Egr1-dependent regulation of transcription.

\section{Egr1 induction precedes the pilocarpine-induced Cacna2d4 mRNA increase}

If Egr1 signaling is required for the augmentation of Cacna2d4, then changes in Egr1 expression should precede those of Cacna2d4. Therefore, we investigated the time course of Egr 1 and Cacna2d4 levels in the pilocarpine-SE model of epileptogenesis. For this purpose, several cohorts of mice were subjected to pilocarpine-induced SE; total hippocampi were isolated $2 \mathrm{~h}$ after pilocarpine-induced SE, whereas hippocampal CA1 subregions were micro-dissected 6 and $12 \mathrm{~h}$ and 3, 10, and $28 \mathrm{~d}$ after pilocarpine treatment. We found Egr1 mRNAs to be rapidly and strongly increased $2 \mathrm{~h}$ after pilocarpine-induced SE (61-fold increase; $p<0.001$ ). Subsequently, levels gradually decayed back to baseline but remained significantly higher $6 \mathrm{~h}$ after pilocarpineinduced SE (18-fold; $p<0.001$ ) (Fig. 2A).

Compared with Egr1, Cacna2d4 expression levels in the pilocarpine-SE model responded in a delayed fashion, so that no marked increase was found for up to $6 \mathrm{~h}$ after pilocarpineinduced SE. However, we observed an increase in Cacna2d4 expression levels that reached significance $12 \mathrm{~h}$ after $\mathrm{SE}$ and persisted for at least $10 \mathrm{~d}$ (Fig. $2 B ; 12 \mathrm{~h}$ : 7.8-fold, $p<0.001 ; 3 \mathrm{~d}$ : 11.1-fold, $p<0.001 ; 10 \mathrm{~d}$ : 12.1-fold, $p<0.001)$. Even in the chronic phase ( $28 \mathrm{~d}$ after SE), mRNA expression levels remained significantly elevated compared with controls (Fig. 2B; 2.3 -fold, $p<0.05)$. These results confirmed that Egr1 augmentation precedes the Cacna2d 4 increase and provided evidence that Egr 1 is a major factor causing the elevated expression of Cacna2d4 in the pilocarpine-induced SE-model of epileptogenesis.

To further collect evidence for a direct coupling of Egr1 and Cacna2d4, we asked whether it is kinetically possible that the protein product of Egr1 mRNA, the Egr1 TF, directly drives expression of Cacna2d4. As the time courses of expression levels of Egr1 (fast decaying) and Cacna2d4 (slowly rising and persistent) differed so markedly, it is almost impossible to visually decide whether a single intermediate reaction product, Egr1 TF, being generated dependent on Egr1 mRNA levels could drive the expression of Cacna2d4, and how complex the underlying reaction schemes need to be. To address this question, we tested whether a system of coupled differential equations representing the simplest model of coupled linear reaction schemes (for details, see Materials and Methods) can sufficiently well be fitted to the data. The observed rapid decay of Egr1 mRNA was well described by a biexponential function and used as input to the model (Fig. 2C, red line). We assumed a generally accepted timing of translation ( $\tau: 6 \mathrm{~h}$ ) (Liu et al., 2016) based on which the model calculated an accumulation of Egr1 protein proportional to the concentration 
A

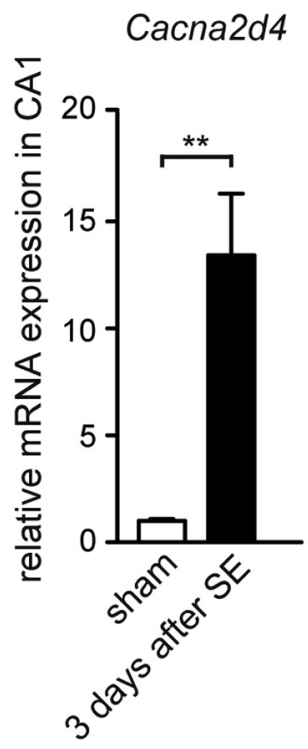

B

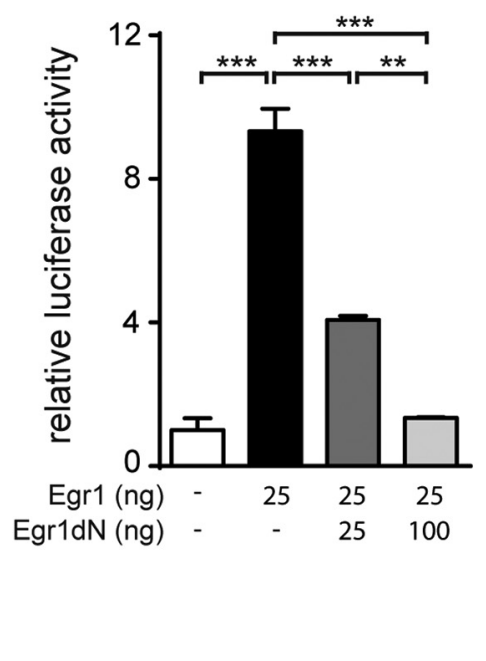

C

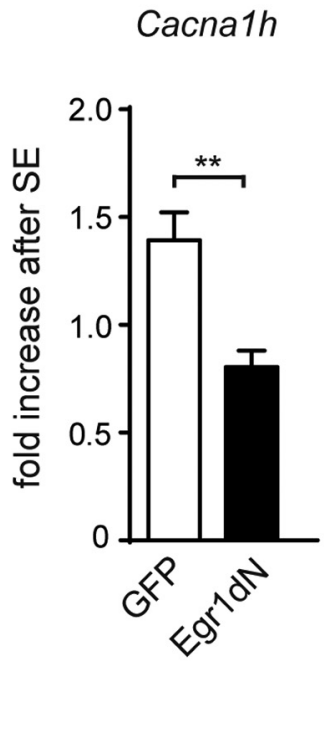

D

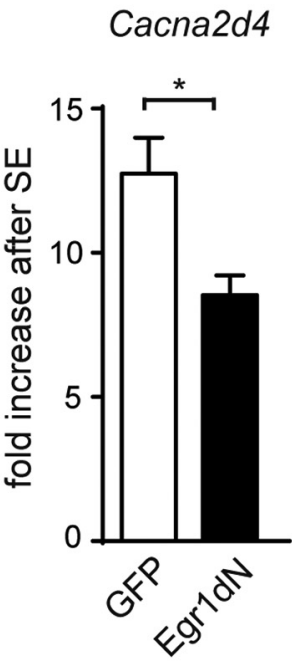

Figure 1. Interference with Egr1 antagonizes pilocarpine-induced augmentation of $\left(a_{v} 3.2\right.$ and Cacna2d4. A, Relative mRNA expression of Cacna2d4 $3 \mathrm{~d}$ after $\mathrm{SE}(n=5)$. ${ }^{* *} p=0.0018$ ( $t$ test). $\boldsymbol{B}$, Luciferase activity of the Ca 3.2 promoter-luciferase reporter gene (Kulbida et al., 2015) after transfection with Egr1 (25 ng) and Egr1dN (25 or $100 \mathrm{ng}$ ) in NG108-15 cells ( $n=3$ ). 0ne-way AN0VA: $p=0.48, F_{(3,8)}=0.91$. Tukey's multiple-comparisons test: ${ }^{* *} p<0.01 ;{ }^{* * *} p<0.001$. C, D, mRNA expression of Cacna1h (C) and Cacna2d4 (D) of mice injected with rAAV-hSyn-GFP (GFP: sham: $n=8 ;$ SE: $n=11)$ and rAAV-hSyn-Egr1dN-2A-mCherry (Egr1dN: sham: $n=9 ;$ SE: $n=10) 3 \mathrm{~d}$ after pilocarpine-induced SE. Cacna $1 h:{ }^{* *} p=0.0012$ ( $t$ test). Cacna2d4: $p=0.012$ ( $t$ test).

increase of Egr1 mRNA. The rate of Cacna2d4 transcription in turn was simplistically also assumed to be proportional to the concentration increase in Egr1 protein $\left(\mathrm{k}_{3}\right)$. For both Egr1 protein and Cacna2d4 mRNA, we assumed a simple first-order decay (depending on time only $\mathrm{k}_{2}, \mathrm{k}_{4}$ ). The fitting procedure numerically evaluated the underlying differential equations (see Materials and Methods) and searched for the optimal set of values for $k_{2}$, $k_{3}$, and $k_{4}$, which minimized the error between the measured and the calculated Cacna2d 4 mRNA levels (Fig. 2C, blue line). As can be seen in Figure $2 C$, this simplistic model indeed closely fits our experimental observations, further substantiating the view of a possible direct causality between Egr 1 and Cacna2d 4 mRNA. Furthermore, the best fit suggests that Egr1 protein shows a slow decay with a time constant of $\sim 2.3 \mathrm{~d}$ and that Cacna2d4 mRNA very slowly accumulates and decays with a time constant of $\sim 7.9$ and $\sim 10.3 \mathrm{~d}$, respectively. These long-time constants also predicted, without further mechanisms or assumptions, the elevated Cacna2d 4 mRNA levels in the chronic phase, $28 \mathrm{~d}$ after SE.

Next, we checked whether Egr1 and Cacna2d4 are expressed in the same cells, making a direct regulation of Cacna2d4 expression by Egr 1 possible. For this, we performed RNAscope, an ultrasensitive and specific in situ hybridization method (Wang et al., 2012), on pilocarpine-induced SE and control slices. In line with our real-time RT-PCR data (Fig. 2B), we observed an increase in Cacna2d4 mRNA signal $6 \mathrm{~d}$ after SE (Fig. 2D). In addition, we observed expression of Cacna2d4 and Egr $1 \mathrm{mRNA}$ in the same cells (Fig. 2E), indicating that Egr 1 could cause the elevated Cacna2d4 expression in epileptogenesis. Together, the results suggest that Egrl can serve as a trigger of long-term transcriptional programs associated with epileptogenesis.

\section{Increase of Cacna2d4 mRNA levels in a different focal epilepsy model}

If the increase of Cacna2d 4 is generally relevant for epileptogenesis, it can also occur in other models of focal epilepsy. Unilateral intracortical injection of KA (Jefferys et al., 2016) induces a focal lesion resulting in unilateral HS and resembles several features of human TLE very closely. Thus, adult mice were injected with KA or saline and killed 1, 2, 3, 5, 10, or $28 \mathrm{~d}$ after injection. We observed a similar delayed time course of the changes in Cacna2d4 mRNA levels, which increased during the first days after KA injection and remained elevated for at least $28 \mathrm{~d}$ after SE (Fig. 2F; 2 d: 8.3-fold increase, $p<0.01$; 3 d: 9.3-fold, $p<0.001$; 5 d: 5.6-fold, $p<0.05 ; 10$ d: 5.3-fold, $p<0.05 ; 28$ d: 29 -fold, $p<$ $0.01)$.

\section{Patients suffering from chronic TLE with HS displayed higher Cacna2d 4 mRNA expression levels}

While human data are not accessible to a detailed time course analysis, we took advantage of the availability of human biopsy specimen from epilepsy patients that underwent surgical resection of epileptic foci, and analyzed Cacna2d4 mRNA levels in the chronic phase of human focal epilepsy (TLE). We compared Cacna2d4 mRNA levels in hippocampal biopsies from pharmacoresistant TLE patients with HS to patients with "lesionassociated" TLE, representing a nonepileptogenic control group (van Loo et al., 2015). Consistent with our findings in mouse models of epilepsy, we observed a significantly higher expression of Cacna2d4 mRNA in hippocampi of patients with HS compared with "lesion-associated" TLE patients ( $p=0.025$, Fig. $2 G$ ). In summary, our data strongly suggest that there is a general epileptogenesis-related increase in Cacna2d4 expression in focal epilepsy across models and species.

\section{Egr1 binds the Cacna2d4 promoter in vitro and in vivo}

To experimentally verify our bioinformatic prediction that Egr1 can bind the Cacna2d4 promoter and regulate Cacna2d4 mRNA expression, we performed ChIP analyses with NG108-15 cells and mouse hippocampi. First, the Cacna2d4 promoter was defined using the Genomatix Software Suite. We detected two TATA boxes and one eponine TSS in the 
A

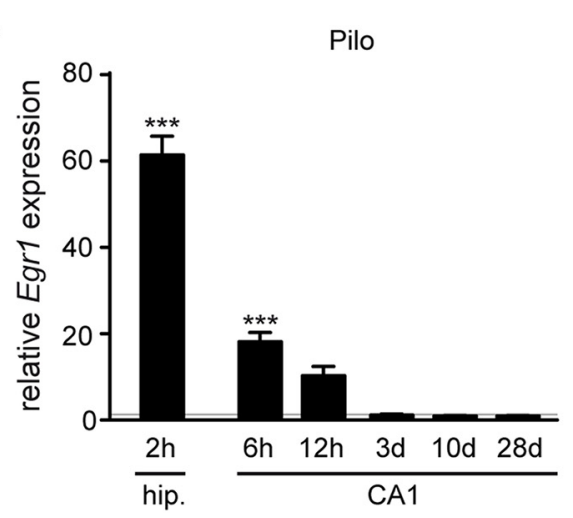

B

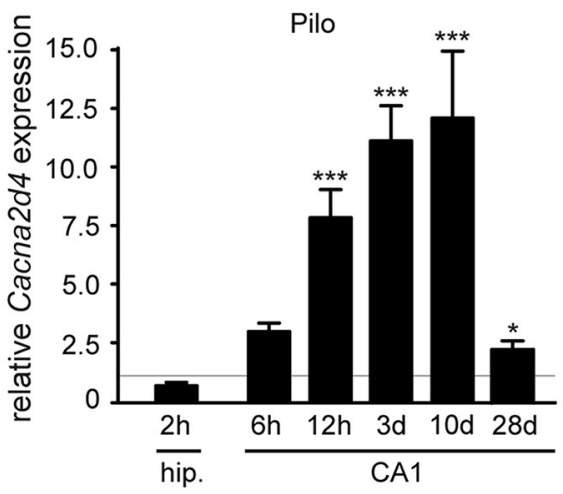

C

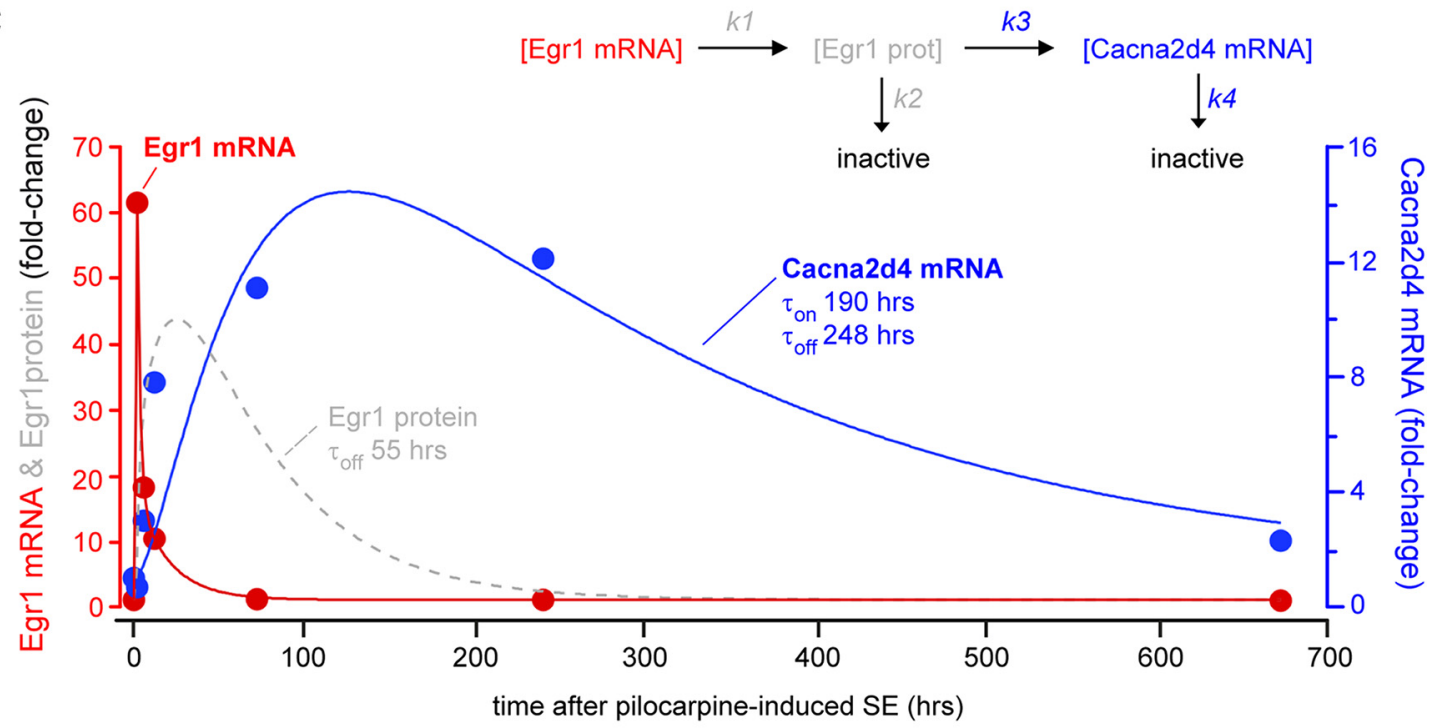

D

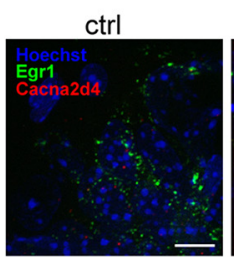

E

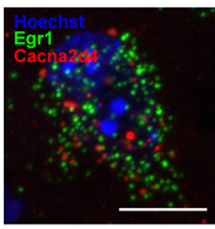

SE
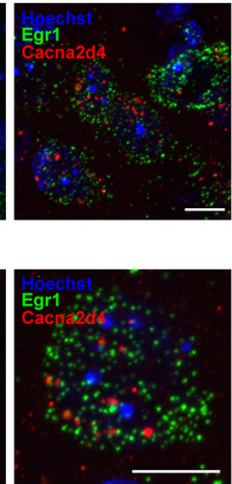

F

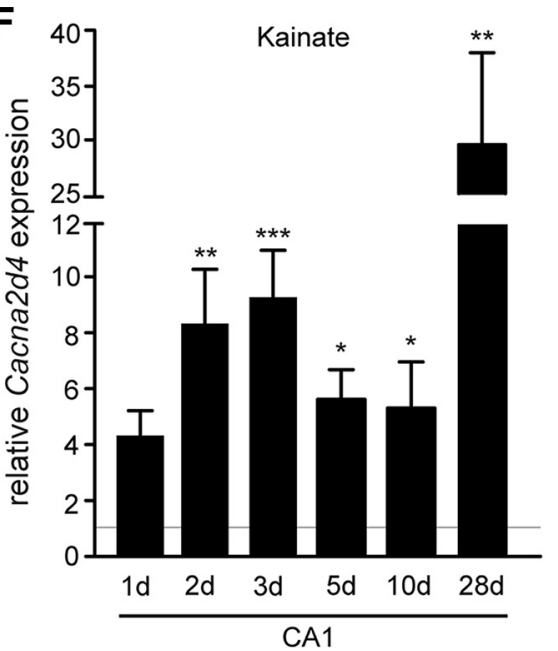

G

Human

hippocampus

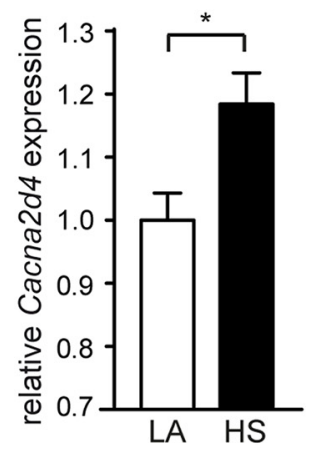

Figure 2. Increase in Cacna2d4 expression in two models for epilepsy. Egr1 $(\boldsymbol{A})$ and Cacna2d4 (B) mRNA expression of total hippocampi $2 \mathrm{~h}$ after pilocarpine-induced SE $(n=8)$ and hippocampal CA1 $6 \mathrm{~h}(n=6), 12 \mathrm{~h}(n=5), 3 \mathrm{~d}(n=5), 10 \mathrm{~d}(n=5)$, and $28 \mathrm{~d}(n=6)$ after pilocarpine-induced SE (Egr1: $2 \mathrm{~h}: 61$-fold increase; $p<0.0001,6 \mathrm{~h}: 18$-fold; $p=0.0002$. Cacna2d4: $12 \mathrm{~h}: 7.8$-fold; $p=0.0005,3 \mathrm{~d}: 11.1$-fold; $p=0.0002,10 \mathrm{~d}: 12.1$-fold; $p<0.0001,28 \mathrm{~d} ; 2.3$-fold). $p=0.03 .{ }^{*} p<0.05$. ${ }^{* * *} p<0.001$. C, Coupled differential equations of Egr1 protein and Cacana2d4 mRNA levels (inset) reveal slow and long-lasting transcriptional regulation following a spike-like increase in Egr1 mRNA. $\boldsymbol{A}, \boldsymbol{B}$, Red and blue circles represent the mean values of $\mathrm{mRNA}$ levels, respectively, following SE. Red line indicates the approximation of Egr1 mRNA by a biexponential function. Dashed gray line indicates relative levels of the assumed intermediary, Egr1 protein. The output of the model well predicts the time course of Cacna2d4 levels between SE and the chronic phase (blue line). For more details, see Materials and Methods. D, Representative pictures of RNAscope hybridization in hippocampal sections of control (left) and pilocarpine-induced SE (right) mice $6 \mathrm{~d}$ after SE using probes targeting Egr1 (green) and Cacna2d4 (red). Hoechst was used to stain the nuclei. Scale bars, $10 \mu \mathrm{m}$. E, Two representative cells expressing both Egr1 (green) and Cacna2d4 (red) mRNA in a hippocampal slice from a pilocarpine-induced SE mice $6 \mathrm{~d}$ after SE. Nuclei stained with Hoechst (blue). Scale bars, $10 \mu \mathrm{m}$. F, Cacna2d4 mRNA expression of hippocampal CA1 1, 2, 3, 5, 10, and $28 \mathrm{~d}$ after KA-induced SE: $1 \mathrm{~d}: 4.3$-fold (sham: $n=8 ;$ SE: $n=7$ ), $2 \mathrm{~d}: 8.3$-fold increase; $p=0.0027$ (sham: $n=6 ;$ SE: $n=5$ ), 3 d: 9.3-fold; $p<0.0001$ (sham: $n=11$;SE: $n=10$ ), 5 d:5.6-fold; $p=0.02$ (sham: $n=8 ;$ SE: $n=7$ ); 10 d: 5.3 -fold; $p=0.03$ (sham: $n=6$; SE: $n=8$ ), $28 \mathrm{~d}$ : 29-fold; $p=0.0036$ (sham: $n=16 ; \mathrm{SE}: n=17$ ). ${ }^{*} p<0.05 .{ }^{* *} p<0.01 .{ }^{* *} p<0.001$ ). G, Cacna2d4 expression in hippocampal tissue of patients with lesion-associated TLE (LA; $n=35$ ) versus hippocampi from patients with $\mathrm{HS}(n=79) .{ }^{*} p=0.025$ ( $t$ test). 
promoter region of Cacna2d4. The core promoter starts $648 \mathrm{bp}$ upstream and ends 100 bp downstream of the TSS and contains six binding sites for Egr1 (Fig. $3 A)$. For the in vitro ChIP experiments, NG108-15 cells were transfected with Egr1 (pAAV-hSyn-Egr1-IRES-Venus); and for the in vivo ChIP experiments, mice were transduced with AAVs harboring Egr1 (rAAV-hSyn-Egr1-IRESVenus) targeting hippocampal CA1 neurons, as described above. We examined the binding of Egrl to the Cacna2d4 promoter by ChIP using an Egr1-specific antibody. A rabbit-IgG isotype control antibody served as negative control for the ChIP reaction, and five different primer pairs were used to cover the Cacna2d4 promoter region (Fig. 3A). Egr1 binding was observed for all predicted binding sites both in NG108-15 cells (Fig. 3B) and in hippocampal neurons (Fig. 3C). These observations clearly demonstrate that Egr1 binds the Cacna2d4 promoter region at multiple sites in neural cells as well as in mouse hippocampi, suggesting Egr1 to be a hub gene in an epileptogenic gene regulatory network.

\section{Induced Cacna2d 4 overexpression in CA1 neurons of the hippocampus} lowers the threshold for PTZ-induced seizure in mice

Our results so far revealed that $\alpha 2 \delta 4$ is strongly increased in CA1 neurons during the period of epileptogenesis, but they do not address whether this augmentation is proconvulsive or anticonvulsive. To explore this question, we experimentally overexpressed $\alpha 2 \delta 4$ in the CA1 area and subjected treated mice to an acute seizure model, the pentylenetetrazole (PTZ)-induced seizure model, with known hippocampal involvement. To this end, mice were injected with rAAV-hSyn-Cacna2d4-mCherry (Cacna2d4 group) or rAAV-hSyn-tdTomato (control group) to specifically transduce neurons in the area CA1 of the hippocampus (Fig. $4 A$ ). Two weeks after viral transduction, Cacna $2 \mathrm{~d} 4$ and control mice were subjected to PTZ treatment, which involved repetitive administration of PTZ (10 mg/kg, i.p.) every 10 min until the occurrence of a first generalized tonicclonic seizure. Interestingly, the latency time until the first seizure was significantly lower in Cacna2d4 mice than in control mice (Fig. 4B). Control animals manifested a generalized seizure after 7.6 injections; whereas in Cacna2d4-injected animals, the first seizure occurred after 6.4 injections $(p<0.05$; Fig. $4 C$ ). This shows that local overexpression of $\alpha 2 \delta 4$ in the CA1 subnetwork of the hippocampus can be sufficient to lower the systemic seizure threshold. Next, we checked whether the susceptibility for PTZ was specific for $\alpha 2 \delta 4$ overexpression or whether other $\alpha 2 \delta$ subunits could also affect seizure susceptibility. Because $\alpha 2 \delta 1$ increases the density of excitatory glutamatergic synapses in developing mouse cortical neurons (Eroglu et al., 2009), it is localized primarily in excitatory presynaptic terminals in the hippocampus (Hill et al., 1993; Bian et al., 2006; Nieto-Rostro et al., 2014), and the mEPSC frequency was reported to positively correlate with the surface expression of the $\alpha 2 \delta 1$ (Cordeira et al., 2014; Zhou and Luo, 2015), we decided to overexpress $\alpha 2 \delta 1$ in the area CA1 of the hippocampus, similar to our $\alpha 2 \delta 4$ experiment, and measured its sensitivity to PTZ treatment 3 weeks after viral infection. In contrast to $\alpha 2 \delta 4$, overexpression of $\alpha 2 \delta 1$ did not have an effect on PTZ susceptibility (time until first seizure: $p=0.61$; number of injections until first seizure: $p=0.79$; Fig. $4 D, E)$.

\section{Cacna2d 4 overexpression dampens network activity in cultured primary hippocampal neurons}

Both KA- and pilocarpine-induced SE, as well as PTZ induction, render limbic structures susceptible for propagation and secondary generalization of epileptiform activity regardless of its origin. To examine how overexpression of Cacna2d 4 affects hippocampal neuronal activity per se, we performed additional in vitro experiments in dissociated hippocampal cultures. Analysis of spontaneous network activity in cultures allowed us to analyze intrinsic network properties in the absence of extrahippocampal sensory inputs and therefore assess the effect of solely $\alpha 2 \delta 4$ increase on neuronal firing. Mouse hippocampal cultures grown on 60 channel MEAs were infected with rAAV-hSyn-Cacna2d4-2A-mCherry at DIV12 after plating. Because we observed a strong increase of $\alpha 2 \delta 4$ mRNA levels 3-10 d after pilocarpine- or KA-induced SE (Fig. $2 B, F)$, the spontaneous network activity was recorded 6,8 , and $10 \mathrm{~d}$ after infection and compared with that obtained from age-matched control cultures. Intriguingly, we found that overexpression of Cacna2d4 led to significant suppression of neuronal firing in cultured hippocampal neurons: 8 and $10 \mathrm{~d}$ after infection both the mean firing rate (reflecting the spike 
A

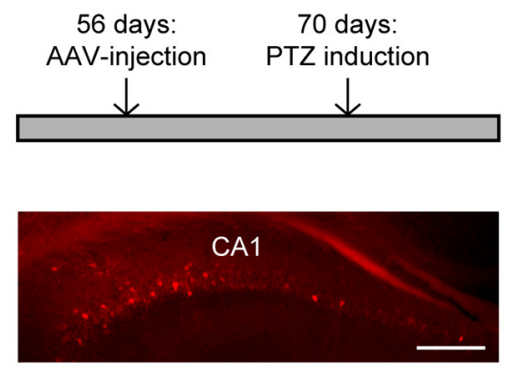

$\mathbf{F}$

control

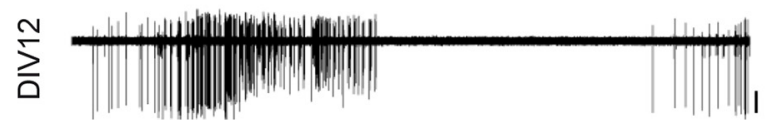

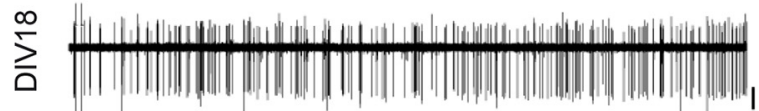
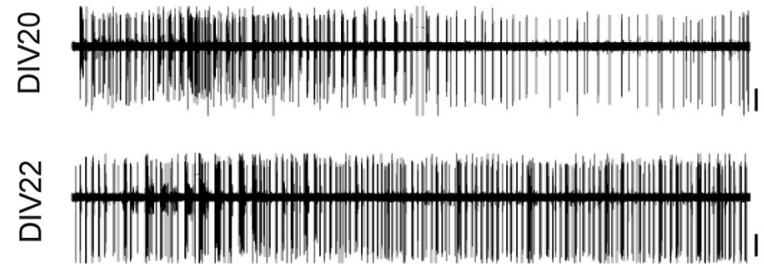

G

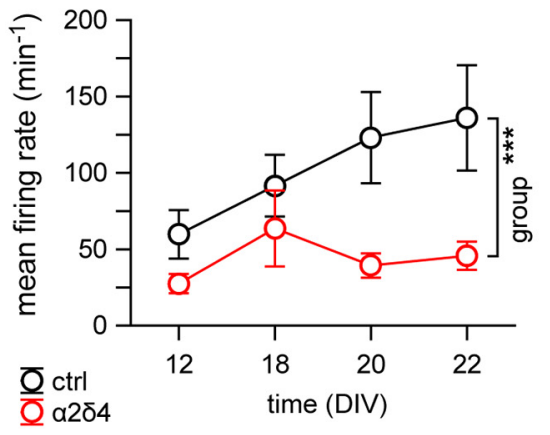

B

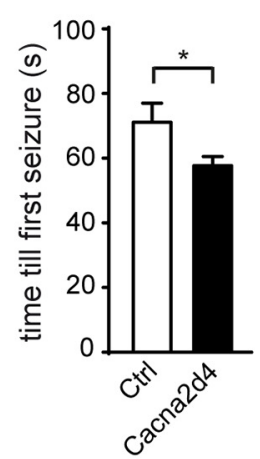

C

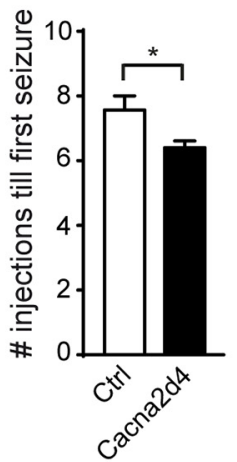

D

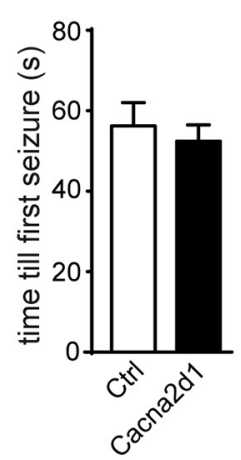

E

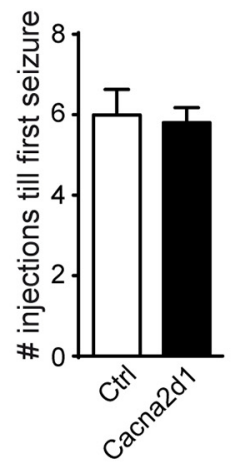

rAAV-hSyn-Cacna2d4-2A-mCherry
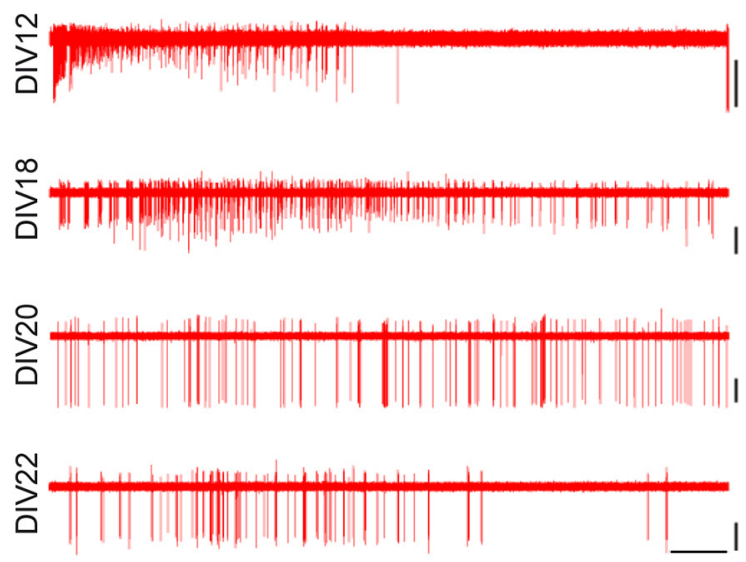

H

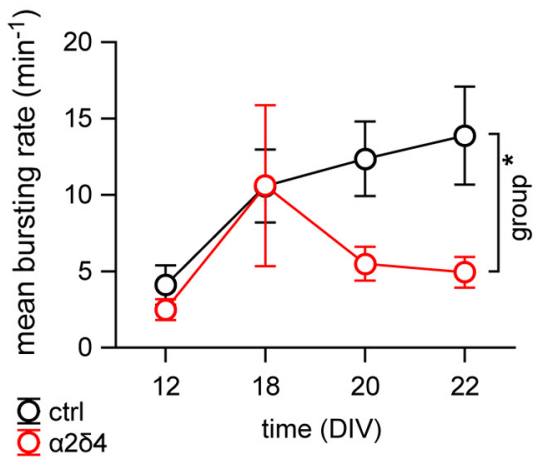

I

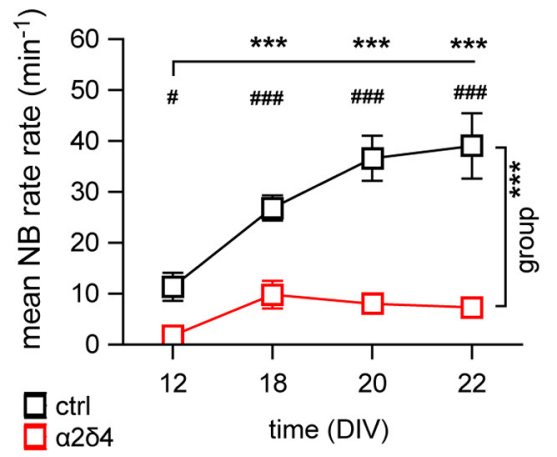

Figure 4. Cacna2d4 has a proconvulsive effect and alters spontaneous network activity. A, PTZ induction in adult mice. Adult mice were injected with rAAV-hSyn-Cacna2d4-mCherry or rAAV-hSyn-tdTomato and tested for PTZ sensitivity $14 \mathrm{~d}$ later. Bottom, Representative picture of an rAAV-hSyn-Cacna2d4-mCherry-injected hippocampus. Scale bar, $200 \mu \mathrm{m}$. B, C, Time until first seizure $(\boldsymbol{B})$ and number of injections until first seizure $(\boldsymbol{C})$ in rAAV-hSyn-tdTomato (ctrl; $n=9)$ and rAAV-hSyn-Cacna2d4-2A-mCherry (Cacna2d4; $n=10$ ) injected animals after injection with PTZ every 10 min. Time until first seizure: ${ }^{*} p=0.04$ ( $t$ test). Number of injections until first seizure: ${ }^{*} p=0.019$ ( $t$ test). D, E, PTZ susceptibility in pLenti-hSyn-Cacna2d1-HA (Cacna2d1; $n=5$ ) and pLenti-GFP (ctrl; $n=5)$ injected mice. Time until first seizure: $p=0.61$ ( $t$ test). Number of injections until first seizure: $p=0.79$ ( $t$ test). $\boldsymbol{F}$, Representative traces of spontaneous neuronal firing derived by an individual electrode at different DIV as indicated in control (left) or $\alpha 2 \delta$-4 overexpressing hippocampal mouse culture (right) grown on 60 channel MEAs. Vertical scale bars: $50 \mu \mathrm{V}$; horizontal scale bars: 20 s. $\boldsymbol{G}, \boldsymbol{H}$, The mean firing $(\boldsymbol{G})$ and bursting $(\boldsymbol{H})$ rates in either naive mouse cultures ( $n=2 \mathrm{MEAs}$ ), or in cultures overexpressing $\alpha 2 \delta 4$ ( $n=3$ MEAs; infection at DIV12 after baseline recording; $2 \mu \mathrm{l}$ per $1 \mathrm{ml}$ of medium). The developmental increase in the neuronal activity is less prominent in $\alpha 2 \delta 4$-overexpressing cultures. Group effect: firing rate, ${ }^{* * *} p<0.001, F_{(1,399)}$ $=11.14$ (two-way ANOVA). Bursting rate: ${ }^{*} p<0.05, F_{(1,184)}=4.57$ (two-way ANOVA).I, The developmental increase of the mean rate of spontaneous network bursts (NB; time effect: $p<0.001$ $F_{(2,192)}=14.48$, two-way ANOVA) was evident under control conditions (***p $<0.001$ within-group comparison with respective values at DIV12, Duncan's post hoc test), but not in $\alpha 2 \delta 4$ overexpressing cultures (group effect: $p<0.001, F_{(1,192)}=108.96$; group $\times$ time interaction: $p=0.001, F_{(1,192)}=6.08$; two-way ANOVA). The effect of $\alpha 2 \delta 4$ overexpression is particularly prominent $8-10 \mathrm{~d}$ after AAV infection. Between-group comparison at respective DIV: ${ }^{\#} p<0.05$ (Duncan's post hoc test); ${ }^{\# \# ~} p<0.001$ (Duncan's post hoc test).

rate of neurons in vicinity of an electrode; between-group $p<$ 0.001, ANOVA) and the number of bursts ( $p<0.05$, ANOVA) were clearly reduced compared with respective values in control cultures (Fig. $4 F-I$ ). The incidence rate of network bursts, which reflect the episodes of synaptically driven functional network interaction between spatially remote neurons, was also markedly lower in $\alpha 2 \delta 4$-overexpressing cultures ( $p<$ 0.001, ANOVA). 


\section{Discussion}

Here, we demonstrate a robust and long-lasting transcriptional augmentation of the VDCC subunit $\alpha 2 \delta 4$ during epileptogenesis tightly controlled by the TF Egr1. Considering the neuronal loss after SE and the fact that Cacna2d 4 is exclusively expressed by neuronal cells whereas we sampled RNA from all cell types, the transcriptional increase is even stronger at the level of an individual neuron. The action of Egr1 in epileptogenesis goes beyond the regulation of Cacna $2 \mathrm{~d} 4$ as it promotes also the activation of $\mathrm{Ca}_{\mathrm{V}} 3.2$, which has been previously demonstrated to convert hippocampal neurons hyperexcitable after SE (Becker et al., 2008). Previously, Egr1 was uncovered to contribute to several processes of epileptogenesis (Hughes and Dragunow, 1994; Beckmann et al., 1997; Rakhade et al., 2007; Helbig et al., 2008; López-López et al., 2017; Lösing et al., 2017), which makes this TF an ideal candidate for a powerful hub gene in an epileptogenic gene regulatory network and opens new vistas for pharmacological intervention by targeting the Egr1-pathway.

The transcriptional increase of Cacna2d 4 was found in two different SE models. Recently, a study analyzing gene expression profiles of three different SE models (intraperitoneal injection of pilocarpine, intraperitoneal injection of KA, and self-sustained SE) revealed a concordance of gene expression of only $4.5 \%$ among the different SE models (Dingledine et al., 2017 ), indicating that only a very low number of genes shows a similar change in gene expression levels in different SE models. This indicates that our observed increase in Cacna2 44 gene expression in the two SE models rather belongs to the fraction of robustly regulated genes. Of course, a $100 \%$ identical expression profile for Cacna2d4 in the KA and pilocarpine model is not expected due to slight differences between the two models (Leite et al., 2002; Jefferys et al., 2016; Lévesque et al., 2016).

The transcriptional increase of Cacna2d4 after SE is rather unexpected, given that $\alpha 2 \delta 4$ shows a distribution restricted to endocrine tissues, where it was shown to be expressed only in specific cells of the adrenal and pituitary glands (Qin et al., 2002). In brain structures, Cacna2d4 is generally absent and only expressed in retinal neurons under physiological conditions (Wycisk et al., 2006a, b). Another study has shown a more ubiquitous distribution of Cacna2d4, albeit with low expression in brain and muscle (Qin et al., 2002). Recently, it has been found that Cacna2d4 expression was strongly increased in hippocampal-like neurons derived from induced pluripotent stem cells in patients with bipolar disorder, with a magnitude of Cacna2d4 augmentation comparable with our results in the two SE models (Mertens et al., 2015). Hippocampal Cacna2d4 expression is thus very low under normal physiological circumstances but can be strongly augmented under pathophysiological conditions, such as bipolar disorder or epilepsy. Considering the expression profile of Cacna2d4, such a large increase of a low-abundant protein might have a stronger cellular and potentially pathological effect than an equivalent increase of a high-abundant protein.

The activation of transcription of Cacna2d4 by Egr 1 after SE resembles closely the temporal kinetics of the T-type channel $\mathrm{Ca}_{\mathrm{V}} 3.2$ (Kulbida et al., 2015). Because the expression of transfected T-type channels is substantial in the absence of $\alpha 2 \delta$ subunits, it is assumed that native T-type channels normally exist without associated $\alpha 2 \delta$ proteins (Perez-Reyes et al., 1998; Lee et al., 1999). Nevertheless, overexpression of $\alpha 2 \delta 1$ and $\beta 1 \mathrm{~b}$ subunits resulted in a twofold increase of the current density of $\mathrm{Ca}_{\mathrm{V}} 3$ channels, and was accompanied by an increase of $\mathrm{Ca}_{\mathrm{V}} 3.2$ and $\mathrm{Ca}_{\mathrm{V}} 3.3$ present at the plasma membrane (Dubel et al., 2004), indicating that $\alpha 2 \delta$ subunits may transiently interact with $\mathrm{Ca}_{\mathrm{V}} 3$ channels and may therefore be considered as a regulatory subunit of T-type calcium channels. However, unfortunately, to date, nothing is known about the impact of $\alpha 2 \delta 4$ subunits in the regulation of $\mathrm{Ca}_{\mathrm{V}} 3$ channels' surface expression and function.

Our results show that experimentally increasing the low levels of $\alpha 2 \delta 4$ in the CA1 region in vivo caused a higher susceptibility for PTZ-induced seizure activity. In addition, elevating $\alpha 2 \delta 4$ levels in hippocampal cultures deprived of extrahippocampal inputs led to suppression of both the neuronal firing and the network interaction. How can the lowered PTZ threshold be reconciled with reduced neuronal activity found in vitro? A key concept explaining this apparent discrepancy may be that rhythmic activity patterns and hippocampal oscillations correspond to a seizure-resistant condition. These ongoing patterns of activity temporally coordinate the discharges of hippocampal neurons in a cell type-specific and phase-locked manner well controlled by the circuits of hippocampal excitatory and inhibitory neurons, such that it is difficult for extra foci of activity to occur and spread. Indeed, it was shown that pharmacological or electrical induction of theta activity in hippocampus counteracts the induction of PTZ-induced seizures (Miller et al., 1994). To robustly maintain its intrinsic rhythms, the hippocampal network requires a certain level of excitability to be able to recruit a sufficient number of neurons into rhythmic firing upon sensory activation, which favors synaptic plasticity. Elevating $\alpha 2 \delta 4$ levels in hippocampal cultures worked against this and decreased the number of neurons involved in network activity. We thus propose that transduction of CA1 neurons in vivo with $\alpha 2 \delta 4$ decreases the propensity of CA1 cells to participate in hippocampal rhythms and, by this, destabilizes the intrinsic and regular patterns of hippocampal activity. This, in turn, renders the hippocampus more vulnerable to epileptiform discharges and their propagation into all-or-none pattern of seizure activity recruiting the whole network. Importantly, analogous reductions of PTZ seizure threshold have previously been documented after decreasing intrinsic or synaptic excitability of hippocampal neurons by elevating NaK-ATPase activity (Funck et al., 2015) or lowering transmitter release (Bröer et al., 2013). Furthermore, we previously observed that mice devoid of the presynaptic active zone protein $\operatorname{RIM} 1 \alpha$, which exhibit a decrease in neurotransmitter release in the hippocampal CA1 region, also experience an increased seizure frequency in the chronic phase after pilocarpine-induced SE (Pitsch et al., 2012).

The $\alpha 2 \delta 4$ subunit is by far less studied than other members of the $\alpha 2 \delta$ family, which makes it difficult to nail down a precise mechanism that might be responsible for reduction of intrinsic, synaptic, and/or network excitability. Nevertheless, recent analyses of $\mathrm{KO}$ mice have revealed essential roles for $\alpha 2 \delta 4$ in modulating $\mathrm{Ca}^{2+}$ channel trafficking and biophysical properties, as well as in presynaptic active zone organization (Wang et al., 2017). Remarkably, $\alpha 2 \delta 4$ was reported to physically interact with the cell adhesion molecule Elfn 1, which in turn binds, depending on the synapse type, to specific metabotropic glutamate (mGlu) receptors (Tomioka et al., 2014; Wang et al., 2017). This interaction affects the presynaptic release probability, for example, at hippocampal oriens-lacunosum-moleculare synapses. Given that both Elfn1 and mGlu7 $\mathrm{KO}$ mice exhibit spontaneous sei- 
zures, it was suggested that reduced Elfn 1 levels might affect network excitability due to disorganized dendritic inhibition by oriens-lacunosum-moleculare interneurons (Tomioka et al., 2014). In rod photoreceptors, $\alpha 2 \delta 4$ is required for the expression and synaptic targeting of Elfn1 (Wang et al., 2017). Thus, an increase of $\alpha 2 \delta 4$ might via Elfn1 reduce release and impair the transmission of information along the hippocampal circuitry. Persistent long-term suppression of activity over days and weeks likely will trigger homeostatic plasticity aimed to restore the physiological levels of activity, resulting in a network prone to propagation and hypersynchronization of excessive epileptiform discharges. In this scenario, RIM $1 \alpha$ and the $\alpha 2 \delta$ family can effectively contribute to increased seizure susceptibility: Both RIM $1 \alpha$ (Castillo et al., 2002) and $\alpha 2 \delta$ (Wang et al., 2016) have been identified as important mediators of presynaptic plasticity that adjusts neurotransmitter release according to ongoing levels of cellular and network activity. Such adaptation is thought to serve as an essential mechanism of keeping the overall excitation/inhibition balance, whereas a failure of activity-dependent adjustment can be associated with predisposition to seizure generation.

Our numerical modeling showed that the long-lasting increase in Cacna2d4 mRNA levels observed after the brief increase in Egr1 levels can be explained with a simple scheme of coupled reactions. Indeed, if the scheme was devised even simpler and the Egr1 protein was omitted, no acceptable fit could be obtained because Cacna2d4 levels still increased while Egr1 mRNA had already decayed back to control levels. On the other hand, we consider it unlikely that more intermediaries than Egr1 are involved, as our ChIP experiment showed that Egr1 itself binds to the Cacna2d 4 promoter. Is the longevity of this transcriptional program of functional importance? Our monitoring of neuronal activity in primary hippocampal neurons addresses this question. Very soon after viral transduction at DIV12, neurons persistently expressed the transduced Cacna2d4 as judged by mCherry levels, thus replicating the time course of Cacna2d4 observed in vivo following SE. Remarkably, the resulting decrease in network activity was fully developed at least $8-10 \mathrm{~d}$ following the viral transduction. This suggests that $\alpha 2 \delta 4$ must be present over long periods of time to exert its effect on the neuronal firing. This raises the question of whether a short-lasting increase of Cacna2d4 can be tolerated and the deleterious consequences of epileptogenesis can be minimized or even completely abolished. This question may be therapeutically relevant as it might allow avoidance of the development of chronic epilepsy by early termination of the transcriptional program activated by SE.

In conclusion, Egrl controls transcriptional expression of $\mathrm{Ca}_{\mathrm{V}} 3.2$ and $\alpha 2 \delta 4$, which act synergistically in epileptogenesis. Future studies may clarify whether the function of Egr1 to orchestrate mRNA signatures during epileptogenesis is even more comprehensive.

\section{References}

Barclay J, Balaguero N, Mione M, Ackerman SL, Letts VA, Brodbeck J, Canti C, Meir A, Page KM, Kusumi K, Perez-Reyes E, Lander ES, Frankel WN, Gardiner RM, Dolphin AC, Rees M (2001) Ducky mouse phenotype of epilepsy and ataxia is associated with mutations in the Cacna2d2 gene and decreased calcium channel current in cerebellar Purkinje cells. J Neurosci 21:6095-6104.

Becker AJ (2018) Review: animal models of acquired epilepsy: insights into mechanisms of human epileptogenesis. Neuropathol Appl Neurobiol 44: 112-129.

Becker AJ, Pitsch J, Sochivko D, Opitz T, Staniek M, Chen CC, Campbell KP,
Schoch S, Yaari Y, Beck H (2008) Transcriptional upregulation of Cav3.2 mediates epileptogenesis in the pilocarpine model of epilepsy. J Neurosci 28:13341-13353.

Beckmann AM, Davidson MS, Goodenough S, Wilce PA (1997) Differential expression of egr-1-like DNA-binding activities in the naive rat brain and after excitatory stimulation. J Neurochem 69:2227-2237.

Bernard C, Anderson A, Becker A, Poolos NP, Beck H, Johnston D (2004) Acquired dendritic channelopathy in temporal lobe epilepsy. Science 305:532-535

Bian F, Li Z, Offord J, Davis MD, McCormick J, Taylor CP, Walker LC (2006) Calcium channel $\alpha 2-\delta$ type 1 subunit is the major binding protein for pregabalin in neocortex, hippocampus, amygdala, and spinal cord: an ex vivo autoradiographic study in alpha2- $\delta$ type 1 genetically modified mice. Brain Res 1075:68-80.

Bikbaev A, Frischknecht R, Heine M (2015) Brain extracellular matrix retains connectivity in neuronal networks. Sci Rep 5:14527.

Brill J, Klocke R, Paul D, Boison D, Gouder N, Klugbauer N, Hofmann F, Becker CM, Becker K (2004) entla, a novel epileptic and ataxic Cacna2d2 mutant of the mouse. J Biol Chem 279:7322-7330.

Bröer S, Zolkowska D, Gernert M, Rogawski MA (2013) Proconvulsant actions of intrahippocampal botulinum neurotoxin $\mathrm{B}$ in the rat. Neuroscience 252:253-261.

Cao XM, Koski RA, Gashler A, McKiernan M, Morris CF, Gaffney R, Hay RV, Sukhatme VP (1990) Identification and characterization of the egr-1 gene product, a DNA-binding zinc finger protein induced by differentiation and growth signals. Mol Cell Biol 10:1931-1939.

Castillo PE, Schoch S, Schmitz F, Südhof TC, Malenka RC (2002) RIM1alpha is required for presynaptic long-term potentiation. Nature 415:327-330.

Catterall WA (2000) Structure and regulation of voltage-gated $\mathrm{Ca}^{2+}$ channels. Annu Rev Cell Dev Biol 16:521-555.

Catterall WA (2011) Voltage-gated calcium channels. Cold Spring Harb Perspect Biol 3:a003947.

Chen J, Sochivko D, Beck H, Marechal D, Wiestler OD, Becker AJ (2001) Activity-induced expression of common reference genes in individual cns neurons. Lab Invest 81:913-916.

Cordeira JW, Felsted JA, Teillon S, Daftary S, Panessiti M, Wirth J, SenaEsteves M, Rios M (2014) Hypothalamic dysfunction of the thrombospondin receptor alpha $2 \delta-1$ underlies the overeating and obesity triggered by brain-derived neurotrophic factor deficiency. J Neurosci 34:554-565.

Dingledine R, Coulter DA, Fritsch B, Gorter JA, Lelutiu N, McNamara J, Nadler JV, Pitkänen A, Rogawski MA, Skene P, Sloviter RS, Wang Y, Wadman WJ, Wasterlain C, Roopra A (2017) Transcriptional profile of hippocampal dentate granule cells in four rat epilepsy models. Sci Data 4:170061.

Dubel SJ, Altier C, Chaumont S, Lory P, Bourinet E, Nargeot J (2004) Plasma membrane expression of T-type calcium channel alpha(1) subunits is modulated by high voltage-activated auxiliary subunits. J Biol Chem 279:29263-29269.

Edvardson S, Oz S, Abulhijaa FA, Taher FB, Shaag A, Zenvirt S, Dascal N, Elpeleg O (2013) Early infantile epileptic encephalopathy associated with a high voltage gated calcium channelopathy. J Med Genet 50:118123.

Ellerkmann RK, Remy S, Chen J, Sochivko D, Elger CE, Urban BW, Becker A, Beck H (2003) Molecular and functional changes in voltage-dependent $\mathrm{Na}(+)$ channels following pilocarpine-induced status epilepticus in rat dentate granule cells. Neuroscience 119:323-333.

Eroglu C, Allen NJ, Susman MW, O’Rourke NA, Park CY, Ozkan E, Chakraborty C, Mulinyawe SB, Annis DS, Huberman AD, Green EM, Lawler J, Dolmetsch R, Garcia KC, Smith SJ, Luo ZD, Rosenthal A, Mosher DF, Barres BA (2009) Gabapentin receptor alpha2 $\delta-1$ is a neuronal thrombospondin receptor responsible for excitatory CNS synaptogenesis. Cell 139:380-392.

Funck VR, Ribeiro LR, Pereira LM, de Oliveira CV, Grigoletto J, Della-Pace ID, Fighera MR, Royes LF, Furian AF, Larrick JW, Oliveira MS (2015) Contrasting effects of $\mathrm{Na}^{+}, \mathrm{K}^{+}$-ATPase activation on seizure activity in acute versus chronic models. Neuroscience 298:171-179.

Gross C, Yao X, Engel T, Tiwari D, Xing L, Rowley S, Danielson SW, Thomas KT, Jimenez-Mateos EM, Schroeder LM, Pun RY, Danzer SC, Henshall DC, Bassell GJ (2016) MicroRNA-mediated downregulation of the 
potassium channel Kv4.2 contributes to seizure onset. Cell Rep 17:37-45.

Hansen KF, Sakamoto K, Pelz C, Impey S, Obrietan K (2014) Profiling status epilepticus-induced changes in hippocampal RNA expression using high-throughput RNA sequencing. Sci Rep 4:6930.

Helbig I, Matigian NA, Vadlamudi L, Lawrence KM, Bayly MA, Bain SM, Diyagama D, Scheffer IE, Mulley JC, Holloway AJ, Dibbens LM, Berkovic SF, Hayward NK (2008) Gene expression analysis in absence epilepsy using a monozygotic twin design. Epilepsia 49:1546-1554.

Hill DR, Suman-Chauhan N, Woodruff GN (1993) Localization of [ $\left.{ }^{3} \mathrm{H}\right] \mathrm{ga}-$ bapentin to a novel site in rat brain: autoradiographic studies. Eur J Pharmacol 244:303-309.

Hino-Fukuyo N, Kikuchi A, Arai-Ichinoi N, Niihori T, Sato R, Suzuki T, Kudo H, Sato Y, Nakayama T, Kakisaka Y, Kubota Y, Kobayashi T, Funayama R, Nakayama K, Uematsu M, Aoki Y, Haginoya K, Kure S (2015) Genomic analysis identifies candidate pathogenic variants in 9 of 18 patients with unexplained west syndrome. Hum Genet 134:649-658.

Ho Sui SJ, Mortimer JR, Arenillas DJ, Brumm J, Walsh CJ, Kennedy BP, Wasserman WW (2005) oPOSSUM: identification of over-represented transcription factor binding sites in co-expressed genes. Nucleic Acids Res 33:3154-3164.

Hughes P, Dragunow M (1994) Activation of pirenzepine-sensitive muscarinic receptors induces a specific pattern of immediate-early gene expression in rat brain neurons. Brain Res Mol Brain Res 24:166-178.

Jefferys J, Steinhäuser C, Bedner P (2016) Chemically-induced TLE models: topical application. J Neurosci Methods 260:53-61.

Johnson MR, Behmoaras J, Bottolo L, Krishnan ML, Pernhorst K, Santoscoy PL, Rossetti T, Speed D, Srivastava PK, Chadeau-Hyam M, Hajji N, Dabrowska A, Rotival M, Razzaghi B, Kovac S, Wanisch K, Grillo FW, Slaviero A, Langley SR, Shkura K, et al. (2015) Systems genetics identifies sestrin 3 as a regulator of a proconvulsant gene network in human epileptic hippocampus. Nat Commun 6:6031.

Kulbida R, Wang Y, Mandelkow EM, Schoch S, Becker AJ, van Loo KM (2015) Molecular imaging reveals epileptogenic $\mathrm{Ca}^{2+}$ channel promoter activation in hippocampi of living mice. Brain Struct Funct 220:30673073.

Laurén HB, Lopez-Picon FR, Brandt AM, Rios-Rojas CJ, Holopainen IE (2010) Transcriptome analysis of the hippocampal CA1 pyramidal cell region after kainic acid-induced status epilepticus in juvenile rats. PLoS One 5:e10733.

Lee A, Wang S, Williams B, Hagen J, Scheetz TE, Haeseleer F (2015) Characterization of Cav1.4 complexes (alpha11.4, beta2, and alpha2 84 ) in HEK293T cells and in the retina. J Biol Chem 290:1505-1521.

Lee JH, Daud AN, Cribbs LL, Lacerda AE, Pereverzev A, Klöckner U, Schneider T, Perez-Reyes E (1999) Cloning and expression of a novel member of the low voltage-activated T-type calcium channel family. J Neurosci 19:1912-1921.

Lee TY, Chang WC, Hsu JB, Chang TH, Shien DM (2012) GPMiner: an integrated system for mining combinatorial cis-regulatory elements in mammalian gene group. BMC Genomics 13 [Suppl 1]:S3.

Leite JP, Garcia-Cairasco N, Cavalheiro EA (2002) New insights from the use of pilocarpine and kainate models. Epilepsy Res 50:93-103.

Lévesque M, Avoli M, Bernard C (2016) Animal models of temporal lobe epilepsy following systemic chemoconvulsant administration. J Neurosci Methods 260:45-52.

Liu Y, Beyer A, Aebersold R (2016) On the dependency of cellular protein levels on mRNA abundance. Cell 165:535-550.

López-López D, Gómez-Nieto R, Herrero-Turrión MJ, García-Cairasco N, Sánchez-Benito D, Ludeña MD, López DE (2017) Overexpression of the immediate-early genes Egr1, Egr2, and Egr3 in two strains of rodents susceptible to audiogenic seizures. Epilepsy Behav 71:226-237.

Lösing P, Niturad CE, Harrer M, Reckendorf CM, Schatz T, Sinske D, Lerche H, Maljevic S, Knöll B (2017) SRF modulates seizure occurrence, activity induced gene transcription and hippocampal circuit reorganization in the mouse pilocarpine epilepsy model. Mol Brain 10:30.

McClelland S, Brennan GP, Dubé C, Rajpara S, Iyer S, Richichi C, Bernard C, Baram TZ (2014) The transcription factor NRSF contributes to epileptogenesis by selective repression of a subset of target genes. Elife 3:e01267.

Mertens J, Wang QW, Kim Y, Yu DX, Pham S, Yang B, Zheng Y, Diffenderfer KE, Zhang J, Soltani S, Eames T, Schafer ST, Boyer L, Marchetto MC,
Nurnberger JI, Calabrese JR, Ødegaard KJ, McCarthy MJ, Zandi PP, Alda M, et al. (2015) Differential responses to lithium in hyperexcitable neurons from patients with bipolar disorder. Nature 527:95-99.

Miller JW, Turner GM, Gray BC (1994) Anticonvulsant effects of the experimental induction of hippocampal theta activity. Epilepsy Res 18:195-204.

Müller CS, Haupt A, Bildl W, Schindler J, Knaus HG, Meissner M, Rammner B, Striessnig J, Flockerzi V, Fakler B, Schulte U (2010) Quantitative proteomics of the Cav2 channel nano-environments in the mammalian brain. Proc Natl Acad Sci U S A 107:14950-14957.

Nieto-Rostro M, Sandhu G, Bauer CS, Jiruska P, Jefferys JG, Dolphin AC (2014) Altered expression of the voltage-gated calcium channel subunit $\alpha(2) \delta$-1: a comparison between two experimental models of epilepsy and a sensory nerve ligation model of neuropathic pain. Neuroscience 283:124-137.

Okamoto OK, Janjoppi L, Bonone FM, Pansani AP, da Silva AV, Scorza FA, Cavalheiro EA (2010) Whole transcriptome analysis of the hippocampus: toward a molecular portrait of epileptogenesis. BMC Genomics 11:230.

Perez-Reyes E, Cribbs LL, Daud A, Lacerda AE, Barclay J, Williamson MP, Fox M, Rees M, Lee JH (1998) Molecular characterization of a neuronal low-voltage-activated T-type calcium channel. Nature 391:896-900.

Pippucci T, Parmeggiani A, Palombo F, Maresca A, Angius A, Crisponi L, Cucca F, Liguori R, Valentino ML, Seri M, Carelli V (2013) A novel null homozygous mutation confirms CACNA2D2 as a gene mutated in epileptic encephalopathy. PLoS One 8:e82154.

Pitkänen A, Engel J Jr (2014) Past and present definitions of epileptogenesis and its biomarkers. Neurotherapeutics 11:231-241.

Pitsch J, Opitz T, Borm V, Woitecki A, Staniek M, Beck H, Becker AJ, Schoch S (2012) The presynaptic active zone protein RIMlalpha controls epileptogenesis following status epilepticus. J Neurosci 32:1238412395.

Qin N, Yagel S, Momplaisir ML, Codd EE, D’Andrea MR (2002) Molecular cloning and characterization of the human voltage-gated calcium channel $\alpha(2) \delta$-4 subunit. Mol Pharmacol 62:485-496.

Rakhade SN, Shah AK, Agarwal R, Yao B, Asano E, Loeb JA (2007) Activitydependent gene expression correlates with interictal spiking in human neocortical epilepsy. Epilepsia 48 [Suppl 5]:86-95.

Royeck M, Kelly T, Opitz T, Otte DM, Rennhack A, Woitecki A, Pitsch J, Becker A, Schoch S, Kaupp UB, Yaari Y, Zimmer A, Beck H (2015) Downregulation of spermine augments dendritic persistent sodium currents and synaptic integration after status epilepticus. J Neurosci 35: $15240-15253$.

Sanabria ER, Su H, Yaari Y (2001) Initiation of network bursts by $\mathrm{Ca}^{2+}$ dependent intrinsic bursting in the rat pilocarpine model of temporal lobe epilepsy. J Physiol 532:205-216.

Su H, Sochivko D, Becker A, Chen J, Jiang Y, Yaari Y, Beck H (2002) Upregulation of a T-type $\mathrm{Ca}^{2+}$ channel causes a long-lasting modification of neuronal firing mode after status epilepticus. J Neurosci 22:3645-3655.

Takahashi M, Seagar MJ, Jones JF, Reber BF, Catterall WA (1987) Subunit structure of dihydropyridine-sensitive calcium channels from skeletal muscle. Proc Natl Acad Sci U S A 84:5478-5482.

Tomioka NH, Yasuda H, Miyamoto H, Hatayama M, Morimura N, Matsumoto Y, Suzuki T, Odagawa M, Odaka YS, Iwayama Y, Won Um J, Ko J, Inoue Y, Kaneko S, Hirose S, Yamada K, Yoshikawa T, Yamakawa K, Aruga J (2014) Elfn1 recruits presynaptic mGluR7 in trans and its loss results in seizures. Nat Commun 5:4501.

Tomita S, Chen L, Kawasaki Y, Petralia RS, Wenthold RJ, Nicoll RA, Bredt DS (2003) Functional studies and distribution define a family of transmembrane AMPA receptor regulatory proteins. J Cell Biol 161:805-816.

van Loo KM, Schaub C, Pernhorst K, Yaari Y, Beck H, Schoch S, Becker AJ (2012) Transcriptional regulation of T-type calcium channel CaV3.2: bi-directionality by early growth response 1 (Egr1) and repressor element 1 (RE-1) protein-silencing transcription factor (REST). J Biol Chem 287: 15489-15501.

van Loo KM, Schaub C, Pitsch J, Kulbida R, Opitz T, Ekstein D, Dalal A, Urbach H, Beck H, Yaari Y, Schoch S, Becker AJ (2015) Zinc regulates a key transcriptional pathway for epileptogenesis via metal-regulatory transcription factor 1. Nat Commun 6:8688.

Vergult S, Dheedene A, Meurs A, Faes F, Isidor B, Janssens S, Gautier A, Le Caignec C, Menten B (2015) Genomic aberrations of the CACNA2D1 
gene in three patients with epilepsy and intellectual disability. Eur J Hum Genet 23:628-632.

Wang F, Flanagan J, Su N, Wang LC, Bui S, Nielson A, Wu X, Vo HT, Ma XJ, Luo Y (2012) RNAscope: a novel in situ RNA analysis platform for formalin-fixed, paraffin-embedded tissues. J Mol Diagn 14:22-29.

Wang T, Jones RT, Whippen JM, Davis GW (2016) $\alpha 2 \delta-3$ is required for rapid transsynaptic homeostatic signaling. Cell Rep 16:2875-2888.

Wang Y, Fehlhaber KE, Sarria I, Cao Y, Ingram NT, Guerrero-Given D, Throesch B, Baldwin K, Kamasawa N, Ohtsuka T, Sampath AP, Martemyanov KA (2017) The auxiliary calcium channel subunit $\alpha 2 \delta 4$ is required for axonal elaboration, synaptic transmission, and wiring of rod photoreceptors. Neuron 93:1359-1374.e6.

Witcher DR, De Waard M, Sakamoto J, Franzini-Armstrong C, Pragnell M, Kahl SD, Campbell KP (1993) Subunit identification and reconstitution of the N-type $\mathrm{Ca}^{2+}$ channel complex purified from brain. Science 261: $486-489$.

Wycisk KA, Budde B, Feil S, Skosyrski S, Buzzi F, Neidhardt J, Glaus E, Nürnberg P, Ruether K, Berger W (2006a) Structural and functional abnormalities of retinal ribbon synapses due to Cacna2d4 mutation. Invest Ophthalmol Vis Sci 47:3523-3530.

Wycisk KA, Zeitz C, Feil S, Wittmer M, Forster U, Neidhardt J, Wissinger B, Zrenner E, Wilke R, Kohl S, Berger W (2006b) Mutation in the auxiliary calcium channel subunit CACNA2D4 causes autosomal recessive cone dystrophy. Am J Hum Genet 79:973-977.

Zhou C, Luo ZD (2015) Nerve injury-induced calcium channel $\alpha-2-\delta$-1 protein dysregulation leads to increased presynaptic excitatory input into deep dorsal horn neurons and neuropathic allodynia. Eur J Pain 19:12671276. 